\title{
MODERNIDADES COLONIALES: LA OBRA DE JUAN MARTÍNEZ DE RIPALDA (1641-1707) COMO RESPUESTA JESUITA EN LA CONTRO- VERSIA UNIVERSITARIA NEOGRANADINA DEL SIGLO XVII
}

\author{
Julián Eduardo Sandoval Bravo* \\ doi:10.11144/Javeriana.uph32-65.mccn
}

\begin{abstract}
RESUMEN
La obra del jesuita Juan Martínez de Ripalda Sobre el uso y el abuso de la doctrina del Divino Tomás (1704) surge como respuesta a las acusaciones doctrinales de la comunidad dominica en la controversia sostenida durante el siglo XVII con la Compañía de Jesús en torno a los privilegios académicos universitarios en el Nuevo Reino de Granada. La obra no solo es un testimonio histórico del pleito, sino que también permite conocer el contenido temático de las enseñanzas filosóficas de la escuela jesuita en la Colonia. El presente artículo ubica el contexto histórico general en que surge la obra para analizar el talante moderno de la doctrina del jesuita Juan Martínez de Ripalda sobre la naturaleza del conocimiento humano.

Palabras clave: periodo colonial; Universidad Javeriana; Universidad de Santo Tomás; tomismo; Nuevo Reino de Granada
\end{abstract}

* FLACSO, Buenos Aires, Argentina.

Correo electrónico: julianedsandoval@gmail.com

Este artículo es resultado de la beca de jóvenes investigadores Colciencias 2012, la cual se desarrolló en el marco del proyecto Modernidades coloniales: la obra de Juan Martínez de Ripalda (16411707) como respuesta jesuita en la controversia universitaria neogranadina del siglo XVII del grupo de investigación Biblioteca Virtual del Pensamiento Filosófico en Colombia, bajo la dirección del Prof. Manuel Domínguez Miranda.

Para citar este artículo: SAndoval Bravo, J.E. (2015). Modernidades coloniales: la obra de Juan Martínez de Ripalda (1641-1707) como respuesta jesuita en la controversia universitaria neogranadina del siglo XVII. Universitas Philosophica, 32(65), pp. 38-80. ISSN 0120-5323, ISSN en línea: 2346-2426, doi:10.11144/ Javeriana.uph32-65.mccn 


\title{
COLONIAL MODERNITIES: JUAN MARTÍNEZ DE RIPALDA'S (1641-1707) WORK AS A JESUIT REPLY IN THE NEOGRANADIANUNIVERSI- TY CONTROVERSY IN $17^{\mathrm{TH}}$ CENTURY
}

\author{
Julián Eduardo Sandoval Bravo
}

\begin{abstract}
The work of the Jesuit Juan Martinez de Ripalda On the use and abuse of Divine Thoma's doctrine (1704) it is a response to the dominical community accusations in the controversy sustained with the Jesuits in the seventeenth century about university academic privileges in the New Kingdom of Granada. The work is not only a historical record of the polemic; it also reveals the thematic content of the philosophical teachings of the Jesuits during the Colonial period. This paper places the general historical context in which the work appeared in order to analyze the modern spirit of the Jesuit Juan Martinez de Ripalda's doctrine on the nature of human knowledge.
\end{abstract}

Key words: colonial period; Javeriana University; St. Thomas University; thomism; New Kingdom of Granada 
En memoria del inolvidable maestro Manuel Domínguez Miranda (1932-2015)

Para que en un pais exista una tradición de pensamiento filosófico no se requiere que la producción haya sido voluminosa en el número de escritos, ni que quienes hayan cultivado este tipo de saber brillen por su originalidad en la historia del espiritu. Lo indispensable es que, siempre, y en cada momento, un grupo de hombres cuya influencia se hace sentir en el contorno social, haya mantenido el contacto con el saber filosófico de su tiempo y con el saber filosófico del pasado. Jaime Jaramillo Uribe

Consideraciones previas

El jesuita Juan Martínez de Ripalda (1641-1707) es considerado como uno de los principales referentes intelectuales en la historia de la Compañía de Jesús en Colombia. Sus méritos como profesor de Artes y Teología Moral, como rector del Colegio Mayor de San Bartolomé, así como su labor de Procurador General de la Provincia del Nuevo Reino de Granada, han sido ampliamente estimados por la mayoría de biógrafos e historiadores de la Compañía de Jesús. Sin embargo, sus aportes más reconocidos tienen que ver con el establecimiento de los jesuitas en tierras neogranadinas, especialmente, con los esfuerzos para conseguir el derecho a otorgar grados académicos en el Colegio de la Compañía de Jesús y, con ello, la aprobación definitiva de la Universidad Javeriana. La consecución de esta aprobación está enmarcada en un pleito sostenido entre jesuitas y dominicos, que revela la lucha entre las dos escuelas religiosas más importantes de la época, para ganar los privilegios y reconocimientos propios del sistema educativo en el Nuevo Reino de Granada. En este contexto se ubica la obra cumbre de Juan Martínez de Ripalda De usu et abusu Doctrinae Divii Thomae (Sobre el uso y el abuso de la Doctrina del Divino Tomás) cuyo propósito último surge a raíz de la confrontación ya nombrada.

Si bien la obra se enmarca dentro de un pleito jurídico sostenido por las dos comunidades religiosas, el texto que produce el padre Ripalda en 1704 no es, como podría pensarse, un simple alegato de carácter jurídico. Se ubica como un tratado de metafísica incluido en un curso filosófico completo que, junto con la lógica y la física, constituían los tres grandes ejes temáticos de la filosofía escolástica que por entonces se enseñaba en los claustros universitarios de la Compa- 
ñía de Jesús. Como respuesta a la acusación de los dominicos, quienes afirmaban que en la Nueva Granada la doctrina de Santo Tomás estaba en inminente peligro de ser desterrada por una mala lectura e interpretación de sus escritos, Ripalda se propone, con esta obra, demostrar que en la Javeriana se sigue la doctrina tomista. En ese entonces, el corpus académico oficial de los claustros universitarios era la síntesis de la filosofía antigua elaborada por Santo Tomás. De hecho, su importancia para el mundo medieval era tal, que se le nombró de manera simbólica como el "Príncipe de los Teólogos" y su obra fue colocada en el mismo nivel que las sagradas escrituras durante el Concilio de Trento. Al respecto, dice el papa León XIII en su encíclica Aeterni Patris del 4 de Agosto de 1879:

Es un hecho constante que casi todos los fundadores y legisladores de las órdenes religiosas mandaron a sus compañeros estudiar las doctrinas de Santo Tomás, y adherirse a ellas religiosamente, disponiendo que a nadie fuese lícito impunemente separarse, ni aun en lo más mínimo, de las huellas de tan gran Maestro. Y dejando a un lado la familia dominicana, que con derecho indisputable se gloria de este su sumo Doctor, están obligados a esta ley los Benedictinos, los Carmelitas, los Agustinos, los Jesuitas y otras muchas órdenes sagradas, como los estatutos de cada una nos lo manifiestan. (Alonso, 1945, p. 38)

En ese sentido, la acusación de los dominicos frente a la Compañía de Jesús equivalía a poner en duda la doctrina jesuita por no ceñirse a las doctrinas religiosas oficiales del Cristianismo. En otras palabras, de manera implícita se acusaba a los jesuitas de enseñar doctrinas divergentes de la enseñanza oficial de los dogmas basados en la lectura rigurosa de la Biblia y la tradición cristiana, aprobados por las autoridades eclesiales. El texto que escribe Ripalda con el objetivo claro de demostrar que en los claustros universitarios de la Compañía de Jesús se enseñan de manera correcta las principales tesis del tomismo imperante, no solo es testimonio del largo episodio histórico que está a la base de la fundación de las dos universidades más influyentes de la Colonia en la Nueva Granada, sino que contiene elementos conceptuales sobre la naturaleza del conocimiento humano, que permiten hacer una lectura distinta del juicio historiográfico tradicional sobre la filosofía del período colonial $^{1}$ en Colombia, el cual sitúa el curso de mate-

$1 \quad$ Al respecto dice Anick Lemperiere (2004): “Colonia se volvió sinónimo de despotismo en lo político y de oscurantismo y poder inquisitorial en lo cultural y religioso (...) La valoración 
máticas dictado por Mutis, en 1760, como el arribo de las ideas modernas e ilustradas a la Nueva Granada.

Dado el carácter polémico y la intencionalidad que se perseguía con la publicación de la obra², se podría afirmar que cualquier estudio sobre este texto colonial se debe centrar en un análisis detallado sobre qué tan correcta es la interpretación de Ripalda de la doctrina de Santo Tomás, confrontando las fuentes que él mismo usa y calificando la fidelidad o no a las ideas del Doctor Angélico ${ }^{3}$. Dicho análisis detallado no solo desborda los límites e intereses del

negativa de "lo colonial" fue la que prevaleció en Hispanoamérica a medida que se perfilaban las dificultades para impulsar las reformas modernizadoras" (p. 107). Esta apreciación de Lemperiere se basa en las perspectivas historiográficas liberales del siglo XIX que para marcar su ruptura con el pasado colonial, lo llamaron "nuestra tardía edad media", dada la supuesta tardanza con que llegan las ideas filosóficas y científicas modernas a la Nueva Granada. Gracias a los trabajos realizados por la BVPFC, se sabe que el sistema copernicano no fue enseñado por vez primera en 1760 , sino que la teoría heliocéntrica ya se conocía en territorios neogranadinos desde 1757 como se demuestra en la recuperación del manuscrito Pyshica specialis et curiosa de Francisco Javier Trías, S.J.. Vale la pena mencionar también que la historiografía conservadora de la Regeneración usó el pasado colonial como justificación de su proyecto político, desde una visión apologética y sobredimensionada. Desde la perspectiva de la nueva historia de Colombia, se ha llegado a apreciaciones más objetivas gracias a los trabajos de Renán Silva y Jaime Jaramillo Uribe, que se destacan por su riguroso trabajo de archivo y su apuesta metodológica por entender la Colonia como un rico campo de investigación aún no estudiado.

2 "Demostrar que quienes en muchos aspectos hacen un uso abusivo de las enseñanzas del Divino Tomás son los padres dominicos, supuestamente representantes de la escuela tomista, mientras que los jesuitas de la Javeriana hacen un uso racional de la doctrina del Doctor Angélico" (Argote \& Del Rey Fajardo, 2007, p. 93)

3 Al respecto, podríamos decir que todos los opúsculos citados por Ripalda son considerados apócrifos por el catálogo presentado por Bartolomé de Capua en 1319 en pleno proceso de canonización de Santo Tomás. Este catálogo consta de 30 opúsculos de autenticidad comprobada y es considerado por los grandes estudiosos de la filosofía tomista - Grabmann, Mandonnet y Gilson- como una suerte de catálogo oficial. Por su parte, la compilación que hace la Biblioteca de Autores Cristianos (BAC) en la edición bilingüe de 2001 de los opúsculos y cuestiones selectas de Santo Tomás, presenta una lista completa y actualizada de todos los opúsculos. Según esta lista, que incluye el catálogo de 1319 así como todas las ediciones e investigaciones de estos escritos (la edición de Piana en 1570, la de Parma en 1582, la de Mandonet en 1927 así como la edición Turinense de 1954 y Leonina de 1969), podemos afirmar que Ripalda basa su argumentación en siete opúsculos cuya inautenticidad ha sido comprobada: De intellectu et intellegibili, Aristotelis totius logicae summae, De sensu respectu singularium et de intellectu respectu universalium, De natura syllogismorum, De natura verbi intellectus, De differentia Verbi divini et humani y De natura generis. En el caso del opúsculo Responsio ad Fratrem Ioannem Vercellensem de quadragintabus articulis, la autenticidad es dudosa, pues aunque aparece en los primeros catálogos, en el último siglo se ha cuestionado dicho escrito (Aquino, 2001, pp. XXIV-XXIX). 
presente artículo, sino que de ningún modo establece conclusiones definitivas sobre las reflexiones filosóficas del maestro neogranadino. En este sentido, hacemos eco de la opinión de Marquínez Argote, para quien Ripalda "muestra un temperamento fuerte y una personalidad independiente en la defensa de sus ideas (...) con la mira puesta en la verdad como último fin, empleando en las cuestiones disputadas la fuerza de los argumentos de razón en primer lugar y sólo después el argumento ab auctoritate" (Argote \& Del Rey Fajardo, 2007, p. 95). El presente trabajo busca analizar los planteamientos de Ripalda, acentuando los problemas filosóficos a los que da respuesta e intentando contextualizarlos con los problemas sociales en que se hallan inmersos y a los que se pretende dar respuesta. De esta manera, hacemos eco de las recomendaciones metodológicas hechas por el padre Fabio Ramírez (1988) en su conferencia "La filosofía en la Colonia": "Hay que volver a aquellas fuentes, naturalmente en latín, para rescatar los catálogos de las bibliotecas coloniales, recordar las biografías y bibliografías de los catedráticos de filosofía, editar las disputas y actos públicos y, con la ayuda de todo esto, realizar estudios monográficos de la época” (p. 59).

Una vez hechas estas consideraciones previas, mostraremos el esquema general del artículo. El primer apartado ubica la obra de Ripalda en el marco del pleito sostenido entre jesuitas y dominicos para lograr el privilegio de otorgar grados académicos universitarios en el Nuevo Reino de Granada. Describimos aquí el origen del pleito y sus características más relevantes, y analizamos el estado de la disputa en los años en que Martínez de Ripalda asume el papel de Procurador de la Compañía de Jesús, para demostrar que la obra del jesuita no se origina en un contexto ingenuo de controversias doctrinales, sino que responde a un interés claro: la consecución del monopolio educativo en el Nuevo Reino de Granada. Una vez ubicados en el contexto general en que se enmarca la obra, analizaremos el contenido temático presente en la Introducción o Disertación Previa, con el fin de identificar los puntos en disputa de la controversia doctrinal entre jesuitas y dominicos y, así, demostrar cómo las ideas de Ripalda sobre la naturaleza del conocimiento humano no son, en efecto, exactamente las mismas que plantea Santo Tomás pero, a pesar de ello, no solo están en consonancia con la doctrina tomista sino que contienen ciertos rasgos cercanos a la reflexión filosófica moderna en torno al tema del conocimiento humano. Para este apartado, nos detendremos en dos aspectos puntuales: la caracterización que hace Ripalda sobre el 
conocimiento humano y su tesis según la cual la creación de conceptos es el objeto y término de la intelección humana.

\section{Un largo y enconado pleito}

EL 13 de JUNIO DE 1580, el papa Gregorio XII expide la bula Romanus Pontifex mediante la cual se establece en el Claustro de Nuestra Señora del Rosario en Santafé “para siempre y sin perjuicio de nadie (...) una Universidad de Estudios Generales con facultades para enseñar todas y cada una de las ciencias permitidas por el Derecho y graduar bachilleres, licenciados, doctores y maestros, con los privilegios de la Universidad de Salamanca” (Ariza, 1980, pp. 23-24). Con esta bula la orden dominicana logró elevar, con todos los privilegios, su convento, fundado en 1550, a la categoría de universidad, con lo que equiparaban la validez de sus títulos a los que se otorgaban en España. De esta manera, los dominicos no solo se alzaron con los mismos privilegios que por entonces gozaban los conventos de México y Lima, donde habían sido fundadas universidades generales, sino ante todo garantizaron ingresos económicos y prestigio social que ayudasen al establecimiento de la orden en tierras neogranadinas. Sin embargo, pese a que la bula de fundación fue expedida en 1580, solo hasta 1639 se dio su ejecución definitiva. Una de las razones por las que tardó la ejecución de la bula fue la aprobación necesaria por parte de las autoridades reales para que las decisiones eclesiásticas pudiesen ejecutarse en territorios de dominio español. Esta figura conocida como Pase Real, fue solicitada por los dominicos en diversas ocasiones, sin obtener respuesta definitiva. Por ejemplo, en 1584 el Rey contestó a la solicitud pidiendo mayor información sobre las fuentes de financiación con que se mantendría a flote la universidad de los dominicos. En palabras del monarca: "Quiero ser informado de qué tanta renta tendrá necesidad la dicha Universidad para los dichos catedráticos, y de qué se le podrá proveer y dotar, que no sea de mi hacienda" (Ariza, 1980, p. 25).

Aunque algunos historiadores sostienen que la no ejecución de dicha bula obedecía a desavenencias y problemas entre la orden dominicana y las autorida- 
des civiles y eclesiásticas de la Nueva Granada ${ }^{4}$, es claro que el principal motivo que frenó el proceso definitivo de fundación de la Universidad de Santo Tomás fue el pleito por el derecho exclusivo a otorgar grados académicos sostenido con la Compañía de Jesús durante todo el siglo XVII. Siguiendo el análisis que hace Renán Silva de la fundación de la cátedra de cánones y decretos a finales del siglo XVII, se evidencia cómo el alegato de los jesuitas, representados por Ripalda, en contra del privilegio exclusivo de los dominicos para otorgar grados académicos, se originó por "[la amenaza] de exclusión [de sus graduados] no solo de la práctica jurídica institucional en los tribunales civiles sino, sobre todo, de las oposiciones para los altos cargos en los tribunales religiosos, de cuyo concurso se les retiraba acusándolos de ilegitimidad en sus estudios y en sus grados" (Silva, 1992, p. 92). Esto nos permite demostrar que la intencionalidad de la obra de Juan Martínez de Ripalda no responde simplemente a discrepancias doctrinales o a diferencias filosóficas ingenuas, sino que se enmarca en una larga lucha de poder por la exclusividad y supremacía en el ámbito educativo del Nuevo Reino de Granada. De esta manera, en un litigio de carácter enteramente jurídico en el que las dos comunidades religiosas pugnan por conseguir el nada despreciable monopolio educativo ${ }^{5}$, se inserta, a manera de argumento, un elemento doctrinal en la disputa entre dominicos y jesuitas, que será la razón por la que Ripalda escribe su obra: demostrar la correcta enseñanza de la doctrina de Santo Tomás en la Academia Javeriana y así conseguir la aprobación definitiva que permitiese a los jesuitas otorgar grados académicos, requisito indispensable para que sus estudiantes alcanzasen ciertas altas dignidades en las jerarquías eclesiástica y civil.

Para una explicación más clara del pleito en cuestión, dividiremos la exposición en tres grandes etapas siguiendo un criterio de segmentación temporal de

4 Podría afirmarse que la malquerencia frente a la orden dominicana radicaba en su reconocida autoridad apostólica y, por ende, en la influencia proveniente de su labor evangelizadora en los territorios de la Nueva Granada, como sugieren Plata Quesada y Reyes Escobar (2005, pp. 88-94).

5 "La universidad colonial, hay que recordarlo de nuevo, no era simplemente un centro de formación intelectual sino un instrumento de intervención en la vida política de la sociedad. (...) La voluntad de privilegio expresaba la guarda celosa de un monopolio, si tenemos en cuenta la conexión que la formación universitaria guardaba con las esferas laborales y de poder social” (Silva, 1992, p. 31). 
acuerdo con las fechas y hechos más relevantes de la larga controversia ${ }^{6}$. Así, hablaremos 1) del origen del pleito en 1599 hasta la querella en torno a la autenticidad de los documentos en 1630;2) de las minucias jurídicas de 1639 hasta el recrudecimiento de la controversia en 1660 y, por último, 3) de la expedición de los breves de Clemente X en 1672 hasta la labor de Juan Martínez de Ripalda como Procurador de la Compañía de Jesús en 1704.

\subsection{DE 1599 a 1630: eL TESTAMENTO DE DON GASPAR NÚNEZ Y LA QUERE- LLA SOBRE LA AUTENTICIDAD DE LOS DOCUMENTOS FUNDACIONALES}

En 1599, el arzobispo de Santafé, Bartolomé Lobo-Guerrero, pide la presencia de la Compañía de Jesús en la Nueva Granada para impulsar la tarea evangelizadora y formadora del nuevo Reino ${ }^{7}$. Gracias a sus buenos oficios, en 1602 el Rey expide una real cédula donde autoriza la fundación de la Compañía de Jesús, la cual se establece en tierras neogranadinas con la fundación del ColegioSeminario de San Bartolomé en 1604, patrocinado por las autoridades eclesiásticas pero dirigido enteramente por los jesuitas ${ }^{8}$.

A la llegada de la Compañía de Jesús la Universidad de Santo Tomás no había logrado constituirse como tal, ya que para ese entonces, no se había ejecutado la bula Romanus Pontifex ni los títulos y privilegios obtenidos, pues en razón de

6 Nos basamos tanto en la periodicidad establecida por José del Rey Fajardo, quien reconstruye en detalle el conflicto sobre las titulaciones universitarias (Fajardo, 2011, pp. 126-155), como en la caracterización de las distintos pleitos identificados por Saranyana a lo largo de la controversia universitaria neogranadina del siglo XVII: el primero por la disposición del legado de Gaspar Núñez (1605-1630); el segundo por el derecho a fundar Universidad Pontificia (1619-1641) y el tercero por el reconocimiento real de la Universidad Javeriana (1641-1701). La identificación que hace Saranyana de tres pleitos distintos en la misma controversia, se basa en la exposición detallada del episodio que hace Juan Manuel Pacheco en los dos primeros volúmenes de su obra Los jesuitas en Colombia (Saranyana, 2005, p. 314).

7 “(...) porque todos han holgado de su venida, y haciéndoles V.M. merced de algunos indios vacos, con que pudiesen sustentarse y edificar, tomarían a su cargo leer las cátedras de teología, artes y gramática, y se podría erigir Universidad que es muy necesaria en esta tierra. Certifico a V.M. en Dios y en mi conciencia, que ningún beneficio se puede hacer en este Reino mayor que mandar funde en él la Compañía y el general de ella provea de religiosos” (Pacheco, 1959, p. 74).

8 La primera fundación del colegio de San Bartolomé fue en 1604, pero su refundación fue realizada el 18 de Octubre de 1605 por el arzobispo Lobo Guerrero. Vale la pena aclarar que el San Bartolomé era Seminario de formación sacerdotal y, a su vez, un Colegio Real y Mayor. Esto significaba que jurídicamente se regía por la autoridad eclesiástica y civil aunque su dirección y administración estuviese a cargo de la Compañía de Jesús (Fajardo, 2011, p. 52). 
la ausencia de fuentes de financiación que permitiesen establecer de manera permanente dicha universidad, no se había logrado el tan anhelado pase real. Frente a este panorama negativo, surgió una inesperada ayuda económica por parte del español Gaspar Nuñez de Figueroa, quien legó en su testamento una buena suma de dinero para donaciones, obras de caridad y fundaciones de distintas obras eclesiásticas, una de ellas a favor de los dominicos. Gracias al aporte económico de don Gaspar Núñez', los dominicos establecieron el nuevo colegio de Santo Tomás en 1608, lugar a donde se trasladó el privilegio exclusivo concedido para el convento del Rosario en la bula Romanus Pontifex, con lo cual los dominicos intentaban establecer definitivamente la Universidad de Estudios Generales. Es en este episodio donde se halla el origen del largo pleito entre dominicos y jesuitas en el que está enmarcada la obra de Ripalda, pues los jesuitas demandaron la fundación de la universidad dominicana justificando su petición en que en el testamento de Gaspar Núñez también había un monto ofrecido para la fundación del Colegio Máximo de la Compañía, que había sido tomado de manera abusiva por los dominicos ${ }^{10}$ : "Que el dicho Gaspar Núñez, antes de su fallecimiento, les ofreció parte de su hacienda para fundar un Colegio de la dicha Compañía (...) y que la dicha orden de Santo Domingo, ha tomado las posesiones y casas que se han comprado, para fundar, el dicho Colegio de su orden" (Ariza, 1980, p. 49).

La demanda se resolvió en 1610 con la expedición de un fallo que otorgó el derecho de fundación a los jesuitas y permitió a los dominicos fundar el Colegio pero con la prohibición de hacerlo con el carácter de universidad originalmente pretendido $^{11}$. De esta forma, el fallo intentaba dar fin, salomónicamente, a la que-

9 "Declaramos y mandamos, que trayendo Dios Nuestro Señor en salvamento la cargación que esperamos, como está referido de los treinta mil pesos que avemos señalado por bienes espirituales de los dos mil pesos que sobran de lo que se señala y aplica para el dicho colegio los mil y cuatrocientos pesos en conformidad de la voluntad del dicho difunto Gaspar Nuñez" (Ariza, 1980, p. 40).

10 Según los datos ofrecidos por la transcripción que hace Alberto Ariza (1993, p. 1399), entre el gran número de disposiciones de don Gaspar en su testamento, la Compañía de Jesús es beneficiaria de 560 pesos.

11 "Os mando que, en conformidad del testamento y disposición del testamento y disposición del dicho Gaspar Núñez, dejéis y consintáis fundar el dicho Colegio para los dichos efectos, favoreciendo este intento, con que no se haga Universidad en el dicho Colegio, y reservando, como reservo su derecho a salvo a la Compañía de Jesús, para que este sea sin perjuicio de su derecho" (Ariza, 1980, pp. 49-50). 
rella, pues aunque la sede de la universidad seguiría siendo el convento del Rosario, los dominicos mantenían su derecho a fundar el Colegio de Santo Tomás, mientras que a los jesuitas les era concedido el derecho a fundar su Colegio Máximo. Sin embargo, este episodio solo marcaba el comienzo de un largo litigio que, en palabras de Guillermo Hernández de Alba, retrasó la cultura, fomentó un irreconciliable espíritu partidista y, ante todo, privó a Santafé de los honores públicos académicos propios de México y Lima (Ariza, 1980, p. 1410) pues, tiempo después, exactamente en Septiembre de 1612, el papa Pablo V, proveniente de la comunidad dominica, emite una bula que autoriza el traslado perpetuo del exclusivo derecho universitario al Colegio de Santo Tomás, una vez este estuviese edificado y adecuado para ello:

Mandamos que la dicha Universidad con todos sus privilegios, gracias, concesiones, favores, exenciones, indultos, asi espirituales como temporales del dicho Convento pase al dicho Colegio, después que estuviere edificado y correctamente dispuesto, y sin perjuicio ajeno, y con consentimiento de los superiores del mismo Colegio, por nuestra Autoridad la trasladamos perpetuamente, y la tengáis como tal. (Ariza, 1980, pp. 52-53)

Mientras tanto, la Compañía de Jesús también intentaba establecer su propia universidad. A raíz de la primera congregación provincial de 1610, la Compañía solicita la facultad para conferir grados en el Colegio-Seminario en Santafé, argumentando que este privilegio conservaría y aumentaría el número de alumnos, entre otras razones ${ }^{12}$. La petición de otorgar grados es concedida en 1611, de acuerdo con los privilegios establecidos por la Compañía, pero condicionada a la aprobación de las autoridades reales bajo la misma figura del pase real que impedía la constitución definitiva de la universidad de los dominicos. A pesar de este negativo antecedente con los dominicos, la Compañía de Jesús decide, dos años después, enviar una súplica al Rey en la que se pide la facultad de conferir grados amparado en la recomendación que hace el arzobispo de Santafé de "conceder a los jesuitas la facultad de dar grados, mientras no exista, como realmente no existe en todo el reino, otra Universidad" (Astrain, 1920, p. 462). La respuesta del Rey llegó en 1616 mediante un breve en el que, aunque no concede el pase real,

12 "Como los padres Dominicanos de esta ciudad tienen una facultad semejante y prometen conferir grados, nuestro Colegio vendría a tierra" (Pacheco, 1959, p. 149). 
el último requisito para la aprobación definitiva de la Universidad, responde en los siguientes términos: "Está bien lo que parece y vea el Consejo si será justo conceder a la Orden de Santo Domingo para su Colegio de Santafé en el Nuevo Reino de Granada la misma facultad que se concede a los de la Compañía, pues se le denegó lo que pretendía de que fuese Universidad" (Astrain, 1920, p. 463).

Por su parte, los dominicos aún mantenían la sede de la universidad en el Convento del Rosario, pues el colegio no tenía recursos propios para sostenerla. En otras palabras, la idea de la Universidad de Santo Tomás se mantenía todavía en proyecto. Sin embargo, en 1617, cuando los jesuitas solicitaron al Papa por intervención del Rey la facultad para dar grados en Filipinas, Chile, Argentina, el Nuevo Reino de Granada y demás partes de las Indias donde no hubiera universidades, los dominicos presentaron una súplica en los mismos términos. Debido a ello, en enero de 1619 se decretó que los obispos y arzobispos de la Nueva Granada pudieran dar grados a quienes hayan hecho cinco años de estudio en los colegios, tanto de jesuitas como de dominicos, que disten 200 millas de las universidades generales, cumplidos todos los requisitos legales. Este decreto, que era válido solamente por 10 años, fue confirmado por el papa Paulo V, quien el 11 de marzo del mismo año expidió el breve Carissimi in Christo donde se ratificaba el derecho concedido en igualdad de condiciones para las dos comunidades (Fajardo, 2011, p. 134). En esos términos, los dos colegios tenían ya la aprobación de las autoridades eclesiales, quienes se reservaban el derecho de conferir grados. Solo faltaba la aprobación de las autoridades reales. No obstante, el Rey se resistió a aprobar el breve en el que se igualaban los derechos con los dominicos y tomó partido por los jesuitas, hasta el punto de lograr que el nuevo Papa Gregorio $\mathrm{XV}$ emitiera, en 1621, otro breve, con los mismos términos, pero otorgándolos de manera exclusiva a los jesuitas:

[se pueden] conceder los grados de bachiller, licenciado, maestro y doctor a todos los que hubieren estudiado cinco años en los colegios de la Compañía de Jesús (...) del Nuevo Reino de Granada y de otras provincias y parte de las mismas Indias, donde no existan Universidades de estudios generales, que disten por lo menos doscientas millas de las Públicas Universidades (...) Por último advierte el Sumo Pontífice, que esta gracia la concede solamente para el espacio de diez años. (Astrain, 1920, pp. 430-431) 
Este breve, titulado In supereminenti, contó rápidamente con la aprobación de las autoridades reales quienes, al cabo de unos cuantos meses, expidieron en marzo de 1622 el pase real que por entonces era requisito indispensable para que las bulas y breves pontificios tuvieran validez en territorios de dominio español. De esta forma, aunque el breve fue aprobado por cédula real en 1622, solo se hizo efectivo hasta el 13 de Junio de 1623, cuando en la Nueva Granada el Colegio Máximo de la Compañía o Academia Javeriana, abría sus puertas de manera formal con la potestad de otorgar grados académicos durante diez años ${ }^{13}$.

Por su parte, los dominicos no cesaban en exigir su derecho argumentando que los distintos documentos expedidos en su favor, no eran sino rectificaciones del breve original del papa Gregorio XIII, por el cual se les concedió la aprobación para erigir una universidad perpetua de Estudios Generales ${ }^{14}$. Con estas y otras razones, los dominicos lograron en 1622 una nueva cédula en la que se otorga el mismo derecho obtenido en el malogrado breve anterior. De esta forma, los dominicos pudieron otorgar en 1626 los primeros grados, tres años después que los jesuitas (Ariza, 1993, p. 1403).

Vale la pena recordar que ninguna de las dos instituciones era todavía una universidad como tal, pues los grados que se otorgaban en los dos colegios estaban determinados por una serie de condiciones muy claras y específicas ${ }^{15}$ que impedían definir estas instituciones como las universidades de México y Lima. En efecto, la Recopilación de leyes de los reinos de las Indias calificaba a estas últimas como universidades oficiales, generales o de estudios generales dado que contaban con

$13 \mathrm{Al}$ respecto dice Pacheco (1959) "Obsérvese bien lo que nos concedía el breve pontificio. No daba facultad para abrir Universidades en todo el rigor de la palabra. Otorgaba solamente lo que más se estimaba en las Universidades, cual era el conferir grados académicos (...) no habían de poseer estos centros docentes todas las dignidades y preeminencias que solían acompañar en Europa a las Universidades Pontificias y Reales, que en América estaban vinculadas por entonces a las de México y Lima" (p. 432).

14 “(...) con Rector y lectores que enseñen todas y cada una de las facultades permitidas por el derecho, y que los estudiantes que en ella cursaren puedan recibir los respectivos grados e insignias de manos del Rector, gozando de todos los privilegios espirituales y temporales concedidos a los que se graduaban en las demás universidades de España" (Medina, 1992, p. 211).

15 “(...) el colegio estuviera ya formado; quedara a más de doscientas millas de la Universidad Real más próxima; los estudios no durasen menos de cinco años; y los candidatos a grados hubieran sido aprobados por el rector y el catedrático o maestro de dicho colegio" (Saranyana, 2005, p. 316). 
los mismos privilegios que los de la niversidad de Salamanca. Entre estos privilegios, se destacaban la intervención directa de la Corona española en su dirección, su financiación proveniente de la real hacienda y la exclusividad del otorgamiento de grados académicos. Por su parte, las universidades que surgen teniendo como base una fundación de conventos o colegios (como en el caso de los dominicos y jesuitas en la Nueva Granada) son las universidades llamadas menores, de categoría inferior, con cátedras y privilegios limitados evidentes en las restricciones para otorgar grados. Las Recopilaciones de Indias las llama simplemente universidades particulares (Rodríguez Cruz, 1973, p. 7). Asimismo, según las Constituciones de la Compañía de Jesús, una universidad no era más que un colegio $^{16}$ en el que a las facultades inferiores de gramática, letras y retórica se le añadían las facultades superiores de artes y teología; por otra parte, debían contar necesariamente con un documento de las autoridades reales y civiles que les aprobase y reconociese el derecho a conferir grados para obtener el título de universidad (Fajardo, 2011, p. 117).

Así, aunque los centros docentes de los dominicos y jesuitas no contaban con las mismas dignidades de las universidades reales, los breves que favorecían a las dos comunidades religiosas les permitieron comenzar a otorgar grados en la Nueva Granada: los jesuitas lo hacían desde 1623 y los dominicos desde 1626. Cada una de las comunidades, ya sin ninguna clase de restricción, hacía valer su derecho sin ninguna preocupación. Sin embargo, el 20 de mayo de 1630 el Consejo Real decretó dar cumplimiento al traslado definitivo del derecho universitario otorgado al convento dominico en Santafé al Colegio de Santo Domingo, por el tiempo en que se había establecido originalmente, es decir, a perpetuidad. De esta manera, se otorgó el aplazado pase real a la bula de 1612 Cathedram Militantis Ecclesiae del papa Paulo V, que era una ratificación y aprobación definitiva de la bula original Romanus Pontifex de 1580 con la que se autorizaba a los

16 Siguiendo la descripción que hace el padre Fabio Ramírez (2002), podemos entender de qué manera funcionaban estos colegios en la época: "Un colegio era una institución de enseñanza donde se impartía todo el currículo de los estudios, desde las primeras letras hasta los estudios superiores: primeras letras, gramática, humanidades, filosofía, teología, y en algunos casos, derecho y medicina. Vivían en él profesores y estudiantes y asistían (gratuitamente) estudiantes externos (solo varones). En él había siempre una iglesia abierta al público, asociaciones religiosas de hombres y mujeres y diversidad de actividades. Estos colegios eran centros de vida cultural y religiosa mucho más allá del campo educativo" (p. 165). 
dominicos a crear de manera perpetua una universidad con los mismos privilegios de la Universidad de Salamanca. Con la obtención del pase real, los dominicos pudieron, por fin, inaugurar su Universidad de Santo Tomás, lo cual, sin embargo, no se hizo sino hasta junio de 1639, nueve años después de obtener la aprobación definitiva y tras 59 años de la bula original. Aunque los historiadores dominicos señalan, con un claro espíritu apologista, que con el reconocimiento oficial y la solemne inauguración ${ }^{17}$ de la Universidad de Santo Tomás el pleito se resolvió a favor de la causa dominicana ${ }^{18}$, lo cierto es que este estaba aún lejos de su solución definitiva.

En efecto, el 17 de agosto de 1639 se prohibió a las dos partes otorgar grados de manera pública por no estar resuelto el litigio de manera concluyente, y en febrero de 1641 se declaró nula toda resolución referente al pleito (Salazar, 1946, p. 559). Por tal motivo, se solicitó a cada una de las comunidades presentar los documentos originales en los que se sustentan los respectivos alegatos. Los jesuitas presentaron los documentos auténticos mientras que los dominicos no hallaron la bula fundamental con la que argumentaban, desde el inicio del pleito, el derecho a crear su universidad: la bula Romanus Pontifex otorgada por Gregorio XIII en 1580. Al ponerse en duda la autenticidad de dicho documento, inició un nuevo y complicado episodio del largo litigio ${ }^{19}$.

17 Ariza transcribe el archivo original en el que se describió la ejecución oficial de la bula y, por ende, la solemne inauguración de la Universidad de Santo Tomás el 4 de Agosto de 1639 mediante un acto público que contó con la presencia de las más altas autoridades civiles y eclesiásticas (Ariza, 1980, pp. 70-72)

18 Con el nacimiento oficial de la Universidad Dominica, la ciudad de Santafé lograba obtener una Universidad de Estudios Generales, lo cual suponía para los jesuitas perder el privilegio de conferir grados a sus discípulos, dadas las condiciones establecidas en que este les fue otorgado (Pacheco, 1959, p. 529)

19 "El ocultamiento de la bula Romanus Pontifex no solo dejaba a los Dominicos sin facultad ni título para conferir grados, sino que acarreaba sobre ellos el perjuicio por la nulidad de todo lo actuado, desde 1609 hasta la inauguración de 1639. Era, pues, necesario obtener de la Santa Sede la confirmación de los privilegios, cuyo título corría el inminente riesgo de perderse, con gran deshonor para la Orden" (Ariza, 1980, p. 108) 


\subsection{DE LAS MINUCIAS JURÍDICAS DE 1639 HASTA EL RECRUDECIMIENTO DE LA CONTROVERSIA EN 1660}

A partir de la QUerella por la AUTENTICIDAd de los documentos, en 1630 inició un nuevo episodio del pleito caracterizado por las constantes peticiones y reclamos de ambas partes para lograr la confirmación de los privilegios académicos concedidos. Para no extendernos en este episodio del pleito, incluimos un cuadro ${ }^{20}$ que resume las peticiones y alegatos de las dos partes durante estos años. Con este breve recuento del debate, procederemos a contextualizar el litigio a la llegada del padre Juan Martínez de Ripalda, en 1663, a la capital del Nuevo Reino de Granada:

\begin{tabular}{|c|c|}
\hline 1639 & $\begin{array}{l}\text { Se suspende el derecho a conferir grados públicos por } \\
\text { orden de la Real Audiencia. }\end{array}$ \\
\hline 1641 & $\begin{array}{l}\text { La controversia llega ante el Consejo de Indias que decla- } \\
\text { ró nulo todo lo realizado en Santafé respecto a la Univer- } \\
\text { sidad de Santo Tomás y se exige a cada una de las partes la } \\
\text { presentación de los documentos auténticos en que funda- } \\
\text { ban sus alegatos. Los dominicos no logran hallar la bula } \\
\text { fundamental Romanus Pontifex de Gregorio XIII con lo } \\
\text { cual se debilita su argumentación. }\end{array}$ \\
\hline 1644 & $\begin{array}{l}\text { El papa Inocencio X expide la bula In Supremo Apostola- } \\
\text { tus Apice mediante la cual se reafirma la autenticidad del } \\
\text { breve de } 1612 \text { de Pablo V sobre el traslado de sede de la } \\
\text { Universidad de Santo Tomás. }\end{array}$ \\
\hline 1651 & $\begin{array}{l}\text { Los jesuitas intentan detener la fundación del Colegio } \\
\text { de Nuestra Señora del Rosario indicando que este hecho } \\
\text { redundaba en contra de la Compañía en el pleito enta- } \\
\text { blado con los dominicos. El Rey decretó que lo uno no } \\
\text { afectaba a lo otro y no atendió su solicitud. }\end{array}$ \\
\hline
\end{tabular}

20 Construido a partir del resumen del pleito consignado en Plata Quesada \& Reyes Escobar, 2005, pp. 113-116. 


\begin{tabular}{|l|l|}
\hline \multirow{1}{*}{1655} & $\begin{array}{l}\text { El Consejo de Indias establece que ninguna de las dos } \\
\text { comunidades religiosas debía tener universidad ni confe- } \\
\text { rir grados. }\end{array}$ \\
\hline \multirow{7}{*}{1660} & $\begin{array}{l}\text { Se determina que los dominicos no pueden dar grados } \\
\text { en cánones, leyes ni medicina y se impide mostrar las bu- } \\
\text { las pontificias y las licencias reales para pelear por estos } \\
\text { privilegios académicos. Por su parte, se rechaza el criterio } \\
\text { de la Compañía según el cual estaban autorizados a otor- } \\
\text { gar grados académicos por una bula de 1561 que solo les } \\
\text { permitía cobijar a los religiosos colegiales jesuitas. A pe- } \\
\text { sar de esta decisión, varios estudiantes seglares recibieron } \\
\text { grados académicos. }\end{array}$ \\
\hline
\end{tabular}

A la llegada de Ripalda a Santafé para iniciar sus estudios universitarios, el pleito entre las dos órdenes religiosas comenzó a agudizarse debido a que la no aparición de la bula original Romanus Pontifex origina la puesta en duda de su existencia efectiva ${ }^{21}$ durante todo el siglo XVII. Asimismo, aunque la Javeriana había logrado constituirse como universidad tanto en estructura burocrática con estatutos, un Rector designado desde Roma, Prefecto, Directores de estudios, Profesorado, Bedeles y estudiantes; como en estructura académica, pues dado su carácter de universidad "particular" o "menor", solamente contaba con las facultades mayores de Artes y Teología, y una facultad menor de Lenguas (Fajardo, 2010, p. 16); el pleito con los dominicos se mantuvo vivo ${ }^{22}$, ya que no se había logrado una constitución legal definitiva. De acuerdo con los informes y peticiones recopilados por Guillermo Hernández de Alba, desde 1660 la Compañía de Jesús buscaba lograr el derecho a otorgar grados de bachiller, maestro y doctor en filosofía y teología (Hernández de Alba y Lesmes, 1969, pp. 225-227). Es decir,

21 Solo hasta 1694 se descubrió la existencia del documento gracias al custodio del Archivo Vaticano quien expidió un testimonio legal en el que certificaba que en los archivos se hallaba constancia de dicha bula (Fajardo, 2011, p. 127).

22 "[El consejo] reconoce las malas consecuencias que de esta controversia se ocasionaban así al interior de ambas religiones, que con esta ocasión se disputaban lo más sagrado de sus antiguos privilegios, como a la causa pública de los moradores de aquellas provincias que entraban a la parte en esta inquietud siguiendo cada cual al bando de su devoción o el parentesco le llevara" (Hernández de Alba y Lesmes, 1969, p. 241). 
constituir legalmente el Colegio Máximo de la Compañía de Jesús como una universidad. En un documento fechado el 13 de octubre de 1683, el colegio de la Compañía buscó prorrogar la facultad de dar grados por diez años más, poniendo en evidencia, una vez más, la controversia entre dominicos y jesuitas:

[E]l Colegio de la Compañía de la ciudad de Santafé en el Nuevo Reino de Granada tenía facultad de graduar en artes y teología a todos los sujetos que estudiasen en su seminario por cierto término (...) y habiéndose controvertido entre la religión de Santo Domingo que también tiene facultad dar grados y la Compañía la forma de darlos, considerando los grandes inconvenientes que podía causar esta controversia en las dos religiones y deseando que se evitasen, dio providencia el consejo de que una y otra graduasen a los estudiantes que cursasen en sus cátedras. (Hernández de Alba y Lesmes, 1969, p. 228)

En los mismos documentos recopilados por Hernández de Alba, entre 1680 y 1685, hay poco más de 10 memoriales, cédulas e informes de la Compañía de Jesús, en su lucha por obtener la facultad de otorgar grados y constituir legalmente su colegio como universidad. Del mismo modo, las respuestas de los dominicos a las insistentes peticiones de los jesuitas son numerosas, pues los procuradores generales de la Orden de Santo Domingo escribieron de manera constante a las autoridades eclesiásticas desde 1644 para garantizar su privilegio exclusivo de otorgar grados $^{23}$. De esta gran cantidad de documentos, destacaremos el breve de Inocencio XI Exponi nubis nuper porque comienza a poner en evidencia la transformación de la controversia, de carácter enteramente jurídico, a una disputa de carácter doctrinal entre dos escuelas teológico-filosóficas contrarias pero con un mismo interés: ganar una posición privilegiada y exclusiva para la formación académica de los dignatarios neogranadinos de las altas jerarquías eclesiásticas y civiles.

1.3 De LA EXPEDICIÓN de LOS BREVES de CLEMENTE X EN 1672 HaSta LA

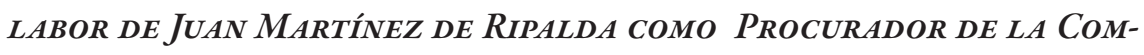
PAÑÍA DE JESÚS EN 1704

EN 1672 y 1675 EL PAPA Clemente X EXPIDIó DOS BREves muy importantes para la Compañía de Jesús. En el primero, fechado el 30 de Mayo de 1672, con-

$23 \mathrm{Al}$ respecto, Ariza construye una breve y precisa cronología de las súplicas y documentos presentados por la orden dominicana desde 1640 hasta la resolución del pleito en 1704 (Ariza, 1980, pp. 108-112). 
cedió a la Compañía de Jesús la aprobación para que los grados otorgados por su colegio se consideraran como conferidos por una Universidad de Estudios Generales. Para lograrlo, el procurador Alonso de Pantoja argumentaba que la universidad más cercana se encontraba a 500 leguas de distancia de Santafé. Por supuesto, el procurador se refería a la universidad de Lima y no a la de Santo Tomás, negando así su existencia y su funcionamiento efectivo desde su solemne inauguración en 1639. En el segundo breve, fechado el 13 de Abril de 1675, el mismo Papa Clemente $\mathrm{X}$ otorgó a maestros y rectores del colegio de la Compañía, la potestad de graduar a sus propios alumnos por un lapso de diez años con la ventaja de que este privilegio no cesara con la erección de una universidad pública en el mismo territorio (Pacheco, 1959, p. 250).

Naturalmente, los dominicos impugnaron estos dos breves y pidieron que se declararan obrepticios, por la exposición de razones falsas, y subrepticios, porque se callaba y ocultaba la verdad. Los dominicos alegaban a su favor que el privilegio de universidad y, por ende, de otorgamiento de grados, lo habían obtenido de manera exclusiva en 1580. Este nuevo episodio del pleito se resuelvió en enero de 1681 cuando se sentenció que ambas comunidades podían seguir graduando de manera privada a sus estudiantes en las facultades y estudios actuales, siempre y cuando no se instituyesen nuevas cátedras ni se otorgasen grados a los estudiantes de otra comunidad que reprobaran sus estudios. Al respecto Pacheco (1959) afirma:

Mandaron que las dichas religiones de Santo Domingo y la Compañía puedan dar grados, como lo están dando, intra claustra (...) pero con la calidad de que no puedan dar dichos grados más que en las facultades de que tuvieran cátedras y estudios actuales (...) Y asimismo mandaron que no pueda una ni otra religión graduar a los que la otra reprobare, ni instituir nuevas cátedras de las facultades que no estuvieren instituidas. (p. 252)

A este decreto, ratificado en agosto del mismo año, se le añadió un privilegio a favor de los dominicos: podían graduar en las facultades y estudios existentes a los estudiantes del Colegio del Rosario, el cual había decidido incorporar sus cátedras a la Universidad de Santo Tomás unos años antes. De esta manera, los dominicos lograron la facultad de graduar en derecho canónico a los estudiantes del Rosario, privilegio que por entonces no tenía la Universidad Javeriana. A raíz de esta situación, en 1682 la Compañía de Jesús pidió al Papa Inocencio XI una 
prorrogación del breve de Clemente X, por el cual otorgaba la potestad de graduar a sus propios alumnos durante diez años más y, también, la facultad de conferir grados en derecho canónico a los alumnos de sus Colegios en Santafé y Quito. Estos privilegios fueron concedidos por el breve Alias felicis de Mayo de 1682. De esta forma, los jesuitas lograban una victoria completa: prorrogar su derecho a otorgar grados durante diez años más y el privilegio de otorgar grados en derecho canónico. A su vez, se desconocía la existencia y funcionamiento de la Universidad de Santo Tomás.

Sin embargo, los dominicos apelaron esta decisión alegando que en el colegio de los jesuitas no existían cátedras de derecho canónico constituidas. Aunque los jesuitas se defendieron argumentando que si bien no existían cátedras de derecho canónico como tal, ellos consideraban la cátedra de teología moral como clase de cánones (Pacheco, 1959). El breve no fue aprobado por las autoridades reales en los términos que proponían los jesuitas. En lugar de ello, en octubre de 1683 se propuso otra resolución en virtud de la igualdad de privilegios de las dos órdenes religiosas:

Por el gran fruto que la religión de la Compañía ha hecho y está haciendo en su enseñanza en la América, con relación al breve obtenido, se pasan oficios con su Santidad para que este sea y se entienda concediendo facultad al Colegio de la Compañía para que pueda graduar en decretos y sagrados cánones a los estudiantes que cursaren en las cátedras que se leen en el colegio del arzobispo (Colegio del Rosario), en la forma que le está permitido y concedido a la religión de Santo Domingo. (Hernández de Alba y Lesmes, 1969, p. 230)

A través de esta consulta se intentó poner fin al largo litigio entre dominicos y jesuitas, otorgando a cada orden los mismos privilegios académicos. Por esta razón, esta propuesta fue llevada a Roma por las autoridades reales para que el Papa Inocencio XI cambiara la declaración del breve Alias felicis. A su vez, los dominicos encargaron al Fray Ignacio de Quesada la tarea de derogar dicho bre$\mathrm{ve}^{24}$ para lograr una declaración oficial y definitiva que ratificase que los colegios de Santo Tomás en Santafé y de San Fernando en Quito eran "Universidades,

24 Esta intervención de los dominicos no fue vista con buenos ojos por las autoridades reales, como se desprende del Informe del fiscal del consejo en el pleito entre la orden de Santo Domingo y la Compañía de Jesús fechado el 24 de Julio de 1685: "[Este] hecho califica no solo la siniestra relación del procurador general sino el exceso con que su religión ha procedido acudiendo a Roma 
ciertas, verdaderas y reales como las de México y Lima” (Ariza, 1980, p. 110). Esta intervención de los dominicos, representados por el padre Quesada, fue compilada en el memorial fechado el 17 de noviembre de 1684, con el cual los dominicos lograron, a través del breve Exponi nobis nuper del Papa Inocencio XI fechado el 11 de abril de 1685, que se les conceda a sus dos colegios las mismas gracias concedidas al colegio-universidad de Santo Tomás en Filipinas. Es decir, lograban que sus dos colegios fueran reconocidos como universidades de estudios generales. Sin embargo, la Compañía de Jesús apeló esta decisión a través del jesuita Pedro Calderón, por entonces Procurador de la provincia del Nuevo Reino de Granada, quien en marzo de 1693 escribió un memorial en respuesta a Fray Ignacio de Quesada donde responde a la pretensión de constituir en universidad a los colegios de Quito y Santafé.

Con estos documentos (el breve Exponi nobis nuper y con los memoriales de los padres Quesada y Calderón), comenzó a surgir la acusación de los dominicos con la que se pone en duda la idoneidad académica de los jesuitas para enseñar la doctrina de Santo Tomás. En palabras del mismo Ripalda, los dominicos en su argumentación "abiertamente advertían del peligro ingente que amenazaba a la doctrina del Divino Tomás de ser desterrada del Nuevo Reino de Granada" (Argote y Del Rey Fajardo, 2007, p. 93). Esta afirmación de Ripalda se confirma con la argumentación que usan los padres Quesada y Calderón, el uno para conseguir y el otro para rebatir, el hecho de que los colegios de Santo Tomás sean declarados como verdaderas universidades. En el memorial del padre Quesada, se afirma que el Colegio de Santo Tomás era una universidad ya erigida que confería grados pero que la única razón por la que se rechazan a sus graduados de los concursos, es seguir la doctrina tomista.

$\mathrm{Al}$ respecto, Pacheco (1959) señala que "algunas personas habían dado en decir que aquellos grados no eran suficientes para oponerse a las dignidades de las catedrales, y con este pretexto sus doctores eran excluidos de los concursos con grave perjuicio de los colegiales y de la doctrina de Santo Tomás, pues no era otro el motivo para no admitirlos que seguir esta doctrina" (p. 254). Sigue el padre Quesada su argumento haciendo una acusación implícita de bastante gravedad:

a controvertir en juicio lo que sólo pendía del político gobierno del consejo, contraviniendo a lo determinado (...) en perjuicio del real patronato" (Hernández de Alba y Lesmes, 1969, p. 246). 
"En todo el reino de Quito no había estudio general ni universidad en que se enseñase la doctrina de Santo Tomás” (Pacheco, 1959, p. 259). De esta manera, se pone en duda la filiación tomista de la enseñanza jesuita como argumento para lograr el privilegio exclusivo del otorgamiento de grados académicos.

Por su parte, el padre Calderón responde en su memorial de 1695 a la acusación dominica, distinguiendo entre la doctrina de Santo Tomás con la llamada doctrina tomista y defendiendo que oponerse a esta última no era oponerse a la del Doctor Angélico, pues los jesuitas seguían en muchos puntos la doctrina de Santo Tomás (Pacheco, 1959, p. 259). El propio Ripalda hace eco de esta argumentación del padre Calderón cuando afirma en la Disertación Previa de su obra:

He escrito todas estas cosas con parca pluma, para que conste cuánto dista nuestro modo de opinar de la mentalidad de los P.P Dominicos, aunque en todo seguimos la mente de Aristóteles y del Angélico Doctor. Luego tomistas somos, si tomista se llama aquel que sigue las huellas del Divino Tomás, nombre del que siempre nos gloriaremos. Pero, con respecto a las opiniones de los P.P Dominicos, mínimamente somos tomistas, como puede verse a lo largo de casi todo nuestro Curso Filosófico. (DP, q.2, lec.IV, n.97) ${ }^{25}$

En este contexto, el padre Martínez de Ripalda asume como Procurador de la Compañía en España, y entre los múltiples asuntos a resolver, se encuentra esta larga controversia. Frente al tema, escribe un memorial sobre la igualdad de los privilegios y facultades de estudios concedidos a las religiones de Santo Domingo y la Compañía de Jesús fechado el 3 de Octubre de 1701. Dice Ripalda:

[A] unque en tan copioso número de cédulas y decretos reales tiene V.M. declarado su real ánimo y voluntad sobre la total igualdad de conferir grados las dos religiones de filosofía, teología, decretos y sagrados cánones (...) no se ha ejecutado la dicha igualdad ni entre las dos religiones ni entre los dichos dos colegios de seculares porque la religión de Santo Domingo gradúa en decretos y sagrados cánones a los colegiales del Rosario que siguen la doctrina tomista. (Hernández de Alba y Lesmes, 1969, p. 382)

25 La citación de la obra de Ripalda la haremos según los criterios establecidos por Marquínez Argote y Del Rey Fajardo en su traducción y estudio del texto original consignado en Vida, obra y pensamiento del maestro javeriano Juan Martínez de Ripalda (1641-1707). Dado que el presente trabajo se basa en la introducción de la obra, no citaremos ningún opúsculo pero mantendremos el formato de citación para la Dissertatio Previae (D.P) con su enumeración original identificando la quaestio (q.), la lectio (lec.) y el número (n.) 
En otras palabras, Ripalda argumenta que la igualdad obtenida en agosto de 1701 respecto al otorgamiento de grados académicos, no se ha ejecutado aún entre la comunidad jesuita y la comunidad dominica porque estos últimos tienen el privilegio exclusivo de graduar en derecho canónico a los colegiales del Rosario que siguen la escuela tomística (Silva, 1992, p. 42). Esta situación que denuncia Ripalda en su memorial, a saber, el hecho de que los dominicos tengan la facultad de graduar a los estudiantes del Rosario, no sería grave si no fuese porque la Compañía de Jesús no tiene, para entonces, ningún privilegio autorizado para otorgar grados, ni establecer cátedras ni facultades de sagrados cánones y decretos. Esto es, el colegio de la Compañía de Jesús carece de los honores y privilegios que fueron otorgados al colegio-universidad de Santo Tomás por el breve Exponi nobis nuper del Papa Inocencio XI. Ante esta situación, Ripalda argumentaba en el mismo memorial, que los colegiales del Rosario tenían todo lo necesario (literatura, cátedras, profesores) para "habilitarse, no solo para los oficios de abogados y otros concernientes a dichas facultades, sino principalmente para oponerse en concurso a las canonjías doctorales" (Hernández de Alba y Lesmes, 1969, p. 382). Por su parte, los colegiales de San Bartolomé, por falta de dichos recursos, se hallaban imposibilitados y excluidos de presentarse al concurso de dichos cargos. Esta desigualdad era evidente en las mismas constituciones del Colegio del Rosario donde, denunció Ripalda, "[no pueden] admitir a cursar las cátedras de cánones, que en él se regentan, a los que no hayan sido estudiantes y colegiales del dicho colegio y cursado primero en él la filosofía de la escuela tomista” (Hernández de Alba y Lesmes, 1969, p. 383). Esto significa para los colegiales de la Compañía que, una vez consumados sus cursos de filosofía y teología, debían pasar al Colegio del Rosario a "profesar las ciencias en que se hallan provectos y aun graduados (...) con lo que se malogran los ingenios y estudiosa afición” (Hernández de Alba y Lesmes, 1969, p. 383), pues no se reconocía que la formación académica javeriana estuviera ceñida a la doctrina de Santo Tomás. Frente a esta acusación doctrinal, enmarcada en la ya mencionada lucha jurídica por obtener el privilegio exclusivo para el otorgamiento de grados académicos, Ripalda publicó en 1704 su obra Sobre el uso y el abuso de la doctrina del Divino Tomás para demostrar que la doctrina de Santo Tomás no era ajena a la enseñanza jesuítica en Santafé.

Hemos visto, de manera breve, el largo pleito sostenido por dominicos y jesuitas en el que se enmarca la obra de Ripalda. Si bien se trata de una obra propia 
de la filosofía escolástica, su objetivo no es solo expositivo, pues se erige como respuesta a una grave acusación doctrinal por parte de los dominicos en el marco de un largo pleito jurídico. De esta manera, la intencionalidad de la obra de Ripalda es demostrar que la Compañía de Jesús es completamente idónea para emitir grados académicos, en virtud de su profunda filiación a la doctrina de Santo Tomás, paradigma de enseñanza durante la época. Vale la pena aclarar que el otorgamiento de grados no era, por sí mismo, el interés principal de estas dos comunidades. Siguiendo la tesis de Renán Silva sobre las corporaciones del saber coloniales, las posiciones de preeminencia y privilegio que subyacían a la disputa entre dominicos y jesuitas, respondían a la configuración de una sociedad en las que estas formas de figuración social resultaban ser parte de los valores sociales supremos. Por ende, es necesario tener en cuenta la posición preeminente que ocupaban los colegios-universidades de las dos comunidades en el entorno social, para situar la disputa ${ }^{26}$ no en términos ingenuos de discrepancias doctrinales, sino como enfrentamientos de poder en un contexto en el que la influencia de estas instituciones educativas eran determinantes para la vida política de la sociedad colonial (Silva, 2004, p. 41).

\section{Diferencias doctrinales entre dominicos y jesuitas}

Hemos visto Cómo La ObRa de Ripalda SURge como respuesta a la controversia en torno a los grados universitarios que tuvo lugar en la Nueva Granada durante el siglo XVII. Sin embargo, aunque esta responde a la acusación de la comunidad dominica en la que se pone en duda la fidelidad de la doctrina jesuita a las tesis del tomismo oficial, no es un episodio aislado de las intensas discusiones doctrinales suscitadas en Europa, pues las disputas y acusaciones de carácter teológico que se presentaron entre dominicos y jesuitas durante el siglo XVII, incidieron en la controversia universitaria que se presentó durante el mismo siglo en el Nuevo Reino de Granada. En efecto, las posiciones teológicas defendidas por los jesuitas en polémicas como las del probabilismo y el regicidio, originaron

$26 \mathrm{Al}$ respecto, dice Silva (2004): "Así mismo, [la posición de preeminencia y privilegio de la institución del saber] entretuvo en pesadas disputas - un tanto anacrónicas a nuestros ojos-, a las distintas órdenes y escuelas, pero que en aquel tiempo resultaban clave, sobre todo en relación con lo que se llamaba "beneficios", pues el privilegio y el poder nunca han sido un intangible" (p. 41). 
una cierta tendencia antijesuítica europea que llegó incluso a culpar a la Compañía de Jesús de la decadencia de los reinos españoles en América. La polémica sobre el probabilismo se sitúa hacia 1577, cuando el dominico Bartolomé de Medina planteó si era lícito seguir una opinión probable (es decir, si está sostenida por sabios y sustentada en argumentos sólidos, aunque la opinión opuesta sea más probable). Esta alternativa surgió en medio de la casuística o moral de casos de conciencia que, aunque fue abandonada por la escuela dominica en 1656, debido a las condenas pontificias a algunos planteamientos (Saranyana, 2005, p. 187), fue acogida enteramente por la escuela jesuita, quienes no distinguieron entre el probabilismo objetivo (opiniones probables sostenidas por sabios) y el probabilismo subjetivo (opiniones probables y subjetivas que surgen ante una duda de conciencia). Por esta razón, la Compañía de Jesús fue acusada de laxitud y superficialidad y, por ende, de ser la causante de la decadencia moral en los reinos de las Américas. A esta acusación, se agregó la de fomentar la desobediencia civil y el desacato a las instituciones monárquicas por enseñar las doctrinas políticas de Francisco Suárez sobre la soberanía popular y de Juan de Mariana sobre la licitud del regicidio en ciertos casos (Saranyana, 2005, p. 188).

Teniendo en perspectiva estas polémicas teólogicas, se puede evidenciar un esfuerzo intelectual por parte de la Compañía de Jesús para configurar su propia doctrina. Según José Luis Fuertes Herreros, se puede dividir este proceso en dos grandes etapas: la primera (1556-1599) estaría constituida por la ruptura de Ignacio de Loyola respecto al sistema medieval, de cara a la formación humanista de los nuevos miembros de la Compañía. Durante esta etapa, según Herreros, se buscaba el equilibrio entre los lineamientos institucionales de carácter aristotélico-tomista, y el nuevo estilo humanista jesuita que buscaba entrar en diálogo con el mundo moderno. De esta etapa, se destaca la figura de Francisco Suárez y su idea de no seguir estrechamente a Santo Tomás. La segunda etapa (1599-1659) se caracteriza por el surgimiento de una identidad propia en la Compañía de Jesús, en la que se da una especie de giro copernicano de la trascendencia a la inmanencia, evidente en la moral práctica y la actitud contemporizadora de la Ratio Studiorum según la cual "el seguir a Santo Tomás no conllevaría el hecho de hacerlo servilmente, y en las cuestiones de filosofía, teología, canónicas y escriturísticas, o cuando el parecer de Santo Tomás fuese ambiguo, dejará libertad para seguir la opinión que mejor pareciere" (Fuertes Herreros, 2006, p. 163). 
Por su parte, la fidelidad doctrinal a las tesis aristotélico-tomistas fue una de las características fundamentales de la enseñanza en la Universidad de Santo Tomás y, como hemos visto, uno de los argumentos empleados por los dominicos para conseguir la potestad de otorgar grados académicos. Esta fidelidad doctrinal se estableció por la Ratio Studiorum de la comunidad dominica y los estatutos elaborados por el arzobispo Fernando Arias de Ugarte y establecidos de manera definitiva en 1639 por el padre Francisco de la $\mathrm{Cruz}^{27}$. A partir de estas fuentes podemos afirmar que dicha fidelidad a las doctrinas y opiniones aristotélico-tomistas no se objetó en ningún momento ${ }^{28}$; incluso los dominicos neogranadinos hicieron eco del Juramento de la Universidad de Salamanca del 19 de junio de $1627^{29}$, con el cual se reafirmaba la adhesión a la doctrina tomista y agustina como un rechazo frente al nuevo modo de hacer teológico y filosófico propugnado por la Compañía de Jesús en sus centros docentes (Fuertes Herreros, 2006, p. 165). De hecho, la profesión de la doctrina tomista era obligatoria en la universidad, e incluso se debía hacer público el juramento de ceñirse a ella y defenderla en todo momento como requisito para recibir cualquier grado (Salazar, 1946, p. 186). En ese sentido, podemos afirmar que la acusación de los dominicos es cierta, pues aunque Ripalda tuviera una clara filiación a las principales

$27 \mathrm{Al}$ respecto, véase: Salazar, 1946, pp. 586-625 y Plata Quesada \& Reyes Escobar, 2005, pp. 124-128.

28 La filiación a la doctrina aristotélico-tomista fue la razón principal para que en 1768 el Fiscal Moreno y Escandón y otros gobernantes ilustrados, afirmaran que esa lealtad a la doctrina tomista contribuía al atraso de los estudios académicos (Salazar, 1946, p. 600). Asimismo, el tomismo fue reafirmado incluso cuando se asomaba la Ilustración, como se evidencia en la decisión del Fr. Juan Tomás de Boxadors (1703-1780), a finales de la década de 1760, de elegir como texto base de la enseñanza filosófica la síntesis tomista realizada por Fr. Antonio Gaudin (1639-1695) quien, aunque había conocido los principales descubrimientos científicos y comparaba los sistemas cosmológicos de Ptolomeo y Copérnico, prefería la doctrina tradicional (Plata Quesada \& Reyes Escobar, 2005, p. 217).

29 "Juramos a Dios Todopoderoso de que en las lecciones que leyéremos en las cátedras, que tenemos o tuviéremos en esta Universidad de Salamanca (...) leeremos y enseñaremos, en la teología escolástica, la doctrina de San Agustín y las conclusiones de Santo Tomás (...) en todo aquello en que fuere clara la mente de estos santos; y donde estuviere dudosa y admitiere varias inteligencias no leeremos ni enseñaremos cosa alguna que sintamos ser contraria a su doctrina". Sobre el juramento, fueron autores y defensores suyos la misma universidad de Salamanca, los dominicos y agustinos. A este se opusieron los franciscanos y los jesuitas, quienes defendían la pluralidad de escuelas y la libertad de enseñanza como elementos consustanciales al ámbito universitario (San-Pedro Rodríguez, 2006, pp. 245-247). 
tesis de Santo Tomás, no hizo una lectura completamente exacta ${ }^{30}$ sobre el tema del conocimiento. No obstante, veremos cómo, a pesar de la validez de dicha denuncia, la lectura no rigurosa ${ }^{31}$ de las tesis tomistas en la obra del jesuita, permite la aparición de un talante filosófico moderno en sus planteamientos sobre la naturaleza del conocimiento humano.

\section{1 ¿ALEGATO JURÍDICO O CONTROVERSIA DOCTRINAL?}

Hemos visto cuál es el estado del pleito cuando Ripalda asume su papel como Procurador de Provincia de la Compañía de Jesús en 1687. Como respuesta al largo conflicto ya descrito, Ripalda, en una clara muestra de su hondo espíritu filosófico, decide trasladar el pleito de los estrados eclesiásticos y judiciales al espacio abierto de la discusión académica, debido a la acusación de orden doctrinal de los dominicos. De esta manera, el conflicto con los dominicos sobre el privilegio para otorgar grados académicos, se transformó en una controversia doctrinal sobre la correcta interpretación del pensamiento de Santo Tomás. En este contexto, Ripalda publicó su obra titulada De usu et abusu Doctrinae Divii Tomae (Sobre el uso y el abuso de la doctrina del Divino Tomás) cuyo objetivo principal era, en sus propias palabras, hacer constar que la doctrina del Divino Tomás no era ajena a la Academia Javeriana en respuesta a la acusación de los dominicos quienes advertían del "peligro ingente que amenazaba a la doctrina del Divino Tomás de ser desterrada del Nuevo Reino de Granada y Quito” (Argote \& Del Rey Fajardo, 2007, p. 93). Esto lo haría compilando los apuntes de las lecciones que dictó a los alumnos javerianos en su papel como catedrático de la Facultad de Artes, de la cátedra de teología dogmática y teología moral durante los años de 1678 a 1684 en Santafé. Dicho material de carácter académico constituyó el

30 Esta lectura se debe, en gran parte, por la inautenticidad de los opúsculos atribuidos a Santo Tomás, pero que por entonces hacían parte del catálogo oficial de la biblioteca jesuita, como puede verse no solo en el catálogo de la Universidad Javeriana colonial sino en su mismo archivo, donde aún se conservan bajo el nombre Opuscula omnia Divi Thomae Aquinates Doctoris Angelici.

$31 \mathrm{Al}$ respecto, se afirma en Los estudios eclesiásticos superiores de la Nueva Granada que los jesuitas trabajaron con más libertad los temas escolásticos y, en ellos, el tomismo. En ese sentido, aunque la doctrina de la Compañía era la doctrina de Santo Tomás, ni a él ni a Francisco Suárez se sigue con un criterio cerrado. Por ello, no faltaron en las polémicas con los dominicos las críticas por su rigidez en la enseñanza y estudio de la filosofía de Santo Tomás (Salazar, 1946, p. 186). 
insumo principal de la obra que se editó y publicó en Lieja (1704), durante la estancia del autor en España (1698-1707).

Aunque el propósito del libro era, como veíamos, mostrar que lo que se enseñaba en la Universidad Javeriana no se apartaba de la doctrina de Santo Tomás para, con ello, desvirtuar la acusación dominicana y lograr la aprobación definitiva de la Universidad Javeriana ${ }^{32}$, Ripalda no construyó un alegato jurídico sino una compleja disertación académica de carácter escolástico sobre temas metafísicos, tales como el principio de la individuación (opúsculo IV), el problema de los universales (opúsculo III) o el tema de la substancia (opúsculos VI y VII). Nos centraremos en la Disertación Previa, por el papel primordial que ocupa en el orden expositivo de su escrito y por ser el lugar de enunciación de las principales posiciones en las que se evidencia las particularidades de la lectura jesuita sobre la doctrina de Santo Tomás. Esta disertación introductoria consta de dos cuestiones, divididas en nueve lecciones que siguen la lógica argumentativa propia de la filosofía escolástica, aunque sin estar invadida de citas y argumentos de autoridad, como podría pensarse. Si bien la permanente referencia a los dos grandes pilares de la filosofía escolástica (Aristóteles y Santo Tomás) es un recurso argumentativo propio de la época, del cual el mismo Ripalda se vale en diversas ocasiones, el jesuita interpreta a estos dos autores para legitimar y sustentar sus propias opiniones. Ahora bien, según los datos biográficos ofrecidos por el padre José del Rey Fajardo (2007, pp. 417-426), Ripalda llegó a América en 1663 para comenzar su formación universitaria en la Universidad Javeriana. Siguiendo el plan de estudios oficial de la Compañía de Jesús, que desde 1599 regía para todos los establecimientos educativos jesuitas, podemos entender el contexto académico en el que Ripalda desarrolla su formación intelectual y su posterior

32 "No pasó desapercibida esta publicación a la crítica occidental pues en 1706 la revista jesuítica francesa conocida como Memories de Trevoux, hacía la reseña del libro de Martinez de Ripalda y a continuación se referían al hecho de que uno de los obejtivos [de su obra] consistía en destruir la tesis que habían difundido los dominicos sobre todo en las altas esferas vaticanas de que los ignacianos en Santafé de Bogotá no enseñaban a Santo Tomás" (Fajardo, 2010, p. 154). Esta reseña se encuentra traducida por el padre Pacheco (1959) de donde extraemos la siguiente cita: "[Los dominicos] habiendo perdido su causa en España, llevaron el asunto a Roma, hicieron ver allí que la doctrina de Santo Tomás corría peligro de ser enteramente abandonada en las Indias [pues] los jesuitas no tenían dificultad alguna en rechazar varias opiniones del Doctor Angélico” (p. 425). 
labor de magisterio, para analizar sus planteamientos sobre la naturaleza del conocimiento humano.

Los estudios de la Facultad de Artes, que se consideraban menores en virtud de su función introductoria a los estudios superiores de la Facultad de Teología, incluían tres grandes bloques conceptuales: Lógica, en el primer año; Física, en el segundo, y Metafísica, en el tercero (Argote \& Del Rey Fajardo, 2007, pp. 3640). Este estricto orden fue seguido por el joven estudiante Ripalda tanto en su formación académica (1663-1670) como en su posterior labor de docencia a cargo de los estudios de la Facultad de Artes (1678-1681). Esta etapa fue determinante, ya que la compilación de sus enseñanzas y lecciones constituyó la materia prima para redactar su obra cumbre: De usu et abusu Doctrinae Divii Tomae. Siguiendo los lineamientos planteados en la Ratio Studiorum ${ }^{33}$, Ripalda enseña en su tercer año a cargo de la Facultad de Artes los temas referentes al estudio del alma de la Metafísica de Aristóteles; sin embargo, reconoce una prevalencia del tema del conocimiento humano frente a los temas propios de la metafísica escolástica. En otras palabras, Ripalda plantea que el tema de entender cómo conoce el entendimiento humano es necesario para entender toda la filosofía. En efecto, la Introducción o Disertación Previa ocupa un lugar principal en la estructura conceptual y temática del libro ya que no es un capítulo más, sino la introducción o puerta de entrada para todos los temas metafísicos allí abordados. Como él mismo afirma: "la doctrina expuesta en esta lección es tan necesaria, que de ella depende no solamente la plena intelección de esta cuestión, sino en gran medida la intelección de toda la filosofía" (D.P, q.1, lec.1, n.13).

Aunque esta idea de Ripalda, según la cual el problema del conocimiento humano es la antesala y la cuestión fundamental de la metafísica, es novedosa frente a la doctrina de Santo Tomás y, en general, a la gran mayoría de filósofos medieva$\operatorname{les}^{34}$, no significa que su propia interpretación de la filosofía tomista no esté basa-

33 Sin embargo, Ripalda se aparta un poco del pensum oficial de los estudios jesuitas pues no dejó para el ámbito de la teología el tema de las Inteligencias, como se sugiere en el punto 218 de la Ratio Studiorum.

34 De hecho, esta es una de las razones por las que se juzga despectivamente las reflexiones de la filosofía escolástica medieval: "Se ha dicho que, en general, los filósofos medievales eran dogmáticos ingenuos pues sus filosofías no llevaban una teoría del conocimiento como prólogo" (Copleston, 1976, p. 49). 
da en una atenta lectura de los textos atribuidos por entonces a Santo Tomás ${ }^{35}$. Partimos, entonces, de un hecho fundamental: Ripalda hace eco en su obra de una profunda filiación a la doctrina de Santo Tomás en lo que tiene que ver con el conocimiento humano. En efecto, en la Disertación Previa, Ripalda anuncia que va a tocar el tema del conocimiento después de haber tratado todos los temas referentes a los ocho libros de la Física de Aristóteles, tema del segundo año de enseñanza en la dicha facultad. Así, el problema del conocimiento humano será el tema con que se inicia la exposición de los asuntos metafísicos, propios del tercer año de enseñanza en la Facultad de Artes. En ese sentido, las reflexiones de Ripalda sobre la naturaleza del conocimiento siempre están referidas a los temas propios del tratado De Anima de Aristóteles según la lectura tomista del Doctor Angélico. Esto significa que, para Ripalda, al igual que para Santo Tomás, el problema del conocimiento humano está enmarcado en una temática más amplia: la naturaleza específica del hombre en virtud de la substancia compuesta que le es propia, a saber, la unidad del alma y cuerpo. Esta naturaleza única del alma humana es la que confiere al hombre no solo las operaciones sensitivas y vegetativas, sino aquella que le es propia, la operación intelectiva: el entender y el razonar. De esta manera, Ripalda sitúa el tema del conocimiento a partir de los postulados aristotélico-tomistas sobre el alma humana -de hecho, él mismo define su curso filosófico como un "tratado del alma" (D.P, q.1. Intro.)-, aunque reconoce la prevalencia de este tema para el correcto aprendizaje de la filosofía.

Por otro lado, en la primera cuestión de la Disertación Previa, Ripalda afirma que ya trató "todo lo relacionado con la vida en acto primero y lo requerido para la ejecución de los actos vitales e intencionales". Ahora, anuncia que lo que se va a exponer es la pregunta por la vida en acto segundo "que por su propia vitalidad supera en mucho a todos los demás actos" y que en modo alguno "ocupa un último lugar en este tratado del alma” (D.P, q.1. Intro.). De esta manera, Ripalda se sitúa de nuevo en una perspectiva aristotélico-tomista según la cual el

35 Aunque la gran mayoría de las citas que usa Ripalda se basan en los Opuscula omnia Sancti Thomae Aquinati, principalmente en los opúsculos apócrifos, Ripalda también sustenta sus opiniones en obras de total autenticidad como la Summa contra gentiles y la Summa Teológica. Al respecto sostienen Marquínez Argote y Del Rey Fajardo (2007): "Poco importa para nuestro caso que Ripalda tome como tomistas textos que no lo son o que interprete mal o bien a Santo Tomás. Lo decisivo es su talante moderno, debido a su instalación en el nuevo horizonte de la subjetividad." (p. 121). 
alma está constituida por facultades o potencias que se diferencian en función de sus actos ${ }^{36}$. Entre estos actos, se diferencian aquellos que son vitales y propios de cualquier ser orgánico (como los apetitos, la locomoción, la nutrición o el crecimiento) de aquellos que son propios del hombre (el intelecto o el razonamiento). Estos últimos, corresponderían a lo que nombra Ripalda como la vida en acto segundo. De esta manera, aunque Ripalda reconoce una prevalencia del conocimiento humano en la reflexión filosófica, es claro que no sitúa el tema del conocimiento a la manera moderna que, ante el triunfo del canon científico de Newton en la comprensión del mundo, busca determinar las posibilidades y alcances de la ciencia frente a otras formas de conocimiento que dicen serlo como, por ejemplo, la metafísica. Ripalda ubica el tema, preguntándose por el objeto propio del acto de la intelección humana y las múltiples respuestas dadas:

Lo primero que hay que afirmar es que, si se pregunta a muchos de los autores más recientes, ¿qué entienden por objeto del entendimiento o qué bajo el nombre de concepto objetivo?, responderán, unos: que los conceptos objetivos no son algo distinto de las cosas mismas existentes fuera del alma (...) Otros, en cambio, sostienen que los conceptos objetivos no son las cosas por doquier existentes tomadas en su nuda realidad o propia naturaleza, en cuanto constituyen el término primario e inmediato del concepto del entender o de la intelección. (D.P, q.2, lec.1, n.53)

En efecto, la idea de justificar la naturaleza de los objetos percibidos en el acto intelectivo es una problemática común a las respuestas que las distintas corrientes realistas, empiristas, racionalistas, idealistas, nominalistas hacen a la pregunta ¿qué es aquello que conocemos cuándo conocemos? Este problema, que es el mismo planteado por Ripalda en la segunda cuestión de su Disertación Previa, donde lo reconoce como un tema propio de la filosofía ${ }^{37}$, tiene que ver con un elemento clave de la teoría del conocimiento: la articulación entre el que conoce y lo conocido (en términos modernos, entre sujeto y el objeto o en términos

36 Estas facultades postuladas por Aristóteles y retomadas por Santo Tomás, son las que constituyen el alma entendida como forma substantialis, o principio vital y fuente de todas las actividades del ser humano.

37 "Gran parte de la Filosofía, para resolver sus dificultades tanto lógicas como metafísicas, emplea estos términos: concepto formal, acto del entendimiento o intelección, cosa conocida o lo concebido" (D.P, q.2. Intro.). 
contemporáneos, entre la mente y el lenguaje). A partir de esta idea, podemos caracterizar la reflexión del jesuita sobre la naturaleza del conocimiento humano en tres grandes rasgos.

En primer lugar, para Ripalda el conocimiento humano es relacional, es decir, aun definiendo el sujeto en un sentido lógico como la idea de la que se afirma o niega algo o en sentido ontológico como la sustancia sobre la que descansan ciertas cualidades o atributos, dicha noción se presenta "como correlato un concepto opuesto privilegiado" (Muñoz \& Velarde, 2000, p. 546). En términos propiamente epistemológicos, dicha oposición se establece entre el sujeto cognoscente y el objeto conocido. Para la filosofía antigua, ese sujeto del conocimiento se identifica con el alma, ${ }^{38} \mathrm{y}$ el objeto del conocimiento, con una realidad extramental, autosubsistente e independiente del sujeto cognoscente. De la misma manera, para Ripalda el conocimiento es, ante todo, una relación entre dos términos: el cognoscente y lo conocido, o lo inteligente y lo entendido. En otras palabras, el conocimiento es una relación entre el sujeto y la realidad, mediante la cual se adquiere noticia de las cosas, sean cosas naturales o cosas ausentes. En palabras de Ripalda:

En lo que es el entender se encierra un doble aspecto: primero, que existe algo que es inteligente; segundo, la existencia de algo que es entendido. Lo que se dice inteligente compete sin controversia alguna a la potencia intelectiva y, mediante tal potencia, al alma o al propio supuesto [persona]. (D.P, q.1, lec.1, n.1)

Según Santo Tomás, el alma está unida indefectiblemente al cuerpo. De allí que se sitúe en un término medio entre el conocimiento sensible (acto de los órganos corporales o sentidos cuyo objeto son las cosas particulares existentes) y el conocimiento angélico (que no es el acto de ningún órgano corporal ni está ligado a ninguna materia y cuyo objeto es la esencia de las cosas mismas). De esta manera, el conocimiento humano está determinado por el compuesto alma y cuerpo en el sentido en que "no es el acto de un órgano corporal, como el sentido, sino que pertenece a un alma, que a diferencia del ángel, es la forma de un cuerpo" (Gilson, 2002, p. 286). De ahí que lo propio del acto del entendimiento

38 "Entendida como alma separada del cuerpo, en el caso de la tradición platónica, o como un alma unida al cuerpo aunque distinguible de él, al modo en que es habitual encontrarla en la tradición aristotélica-tomista” (Muñoz \& Velarde, 2000, p. 546). 
humano sea conocer la forma o esencia de las cosas, las cuales existen individualmente en la materia corporal, pero abstrayéndolas de esas determinaciones materiales o corpóreas:

Lo mismo que podemos considerar aparte el color de un fruto sin tener en cuenta sus otras propiedades, nuestro intelecto puede considerar por separado, en los fantasmas de la imaginación, lo que constituye la esencia del hombre, del caballo o la piedra, sin tener en cuenta lo que distingue tales o cuales individuos determinados. (Gilson, 2002, p. 286)

Así, todo acto de conocimiento supone la abstracción de los elementos universales e inteligibles de los elementos particulares, materiales y corpóreos de las cosas. Por ello, Tomás se pregunta por el cómo puede un cognoscente, a quien lo inteligible le llega inmerso en lo sensible, conocer lo que son las cosas mismas a pesar de dichas determinaciones materiales. Para ello, Tomás propone que el intermediario entre uno y otro ${ }^{39}$ es la especie definida no como aquello que el pensamiento conoce de la cosa sino aquello mediante el cual el pensamiento conoce la cosa (Gilson, 2002, p. 297). En otras palabras, para Santo Tomás la especie (también llamada verbo mental o concepto objetivo) es el medio con el que entendemos algo o aquello con lo que es conocido en forma inmediata la cosa misma (Argote \& Del Rey Fajardo, 2007, p. 123).

En segundo lugar, el conocimiento humano es inmanente. Según Danilo Cruz Vélez "[la metafísica de la subjetividad] le atribuye al sujeto humano una posición preeminente en la relación sujeto-objeto. El sujeto se traga al objeto, y se convierte en el fundamento que determina la objetividad de todos los objetos" (Cruz Vélez, 1977, p. 121). Es decir, en la concepción del conocimiento que se inaugura con Descartes, el sujeto de conocimiento es ahora una sustancia pensante, con la

39 "Lo sensible es la unión de una forma, y en consecuencia de un inteligible, con una materia determinada. Lo sensible contiene, pues, lo inteligible en potencia determinado en acto [...]. Del lado del hombre, se encuentra también lo inteligible en acto, su intelecto [...] pero este inteligible es indeterminado, es una luz por la que se puede ver, pero en la que no se ve nada. Para que nos permita ver, es preciso que encuentre objetos, es preciso que existan algunos que se le muestren. Lo inteligible en acto que es nuestro intelecto morirá de inanición si no encuentra su alimento en en el mundo en que estamos colocados. No lo encontrará más que en lo sensible: la solución tomista del problema del conocimiento será [...] que lo sensible, determinado en acto e inteligible en potencia, pueda comunicar su determinación a nuestro intelecto, que es inteligible en acto, pero determinado sólo en potencia” (Gilson, 2002, p. 288). 
misma tarea de mediación y conexión con el mundo extramental, pero que ya no se configura desde la perspectiva arisotélico-tomista de la asimilación ${ }^{40}$, sino desde la representación del mundo externo a través de ideas o nociones que son las que el sujeto conoce de forma inmediata. Por su parte, Ripalda constantemente plantea que el conocimiento humano es un acto personal y subjetivo, propio del ser humano. Así, sostiene que en el acto del entendimiento (es decir, la relación entre el que conoce y lo conocido) lo entendido no existe fuera del alma o del sujeto inteligente. Es decir, otorga un carácter inmanente a la naturaleza de la operación intelectiva. Para Ripalda, esto es evidente por experiencia cuando en el aquí y ahora entendemos cosas ausentes que, aun sin estar presentes, lo están en el entendimiento. Por ejemplo, cuando soñamos que un toro nos persigue, que encontramos grandes riquezas o que nos encontramos con un amigo que vive en otro país. Es así como el entendimiento conoce en acto muchas cosas que no existen realmente. En palabras de Ripalda, todas esas cosas existen actual y objetivamente solo en el entendimiento, solo en la persona misma y en ningún otro lugar (D.P, q.1, lec.3, n.23-24; D.P, q.1, lec.2, n.19). En este sentido, es clara la referencia a la doctrina aristotélico-tomista en la que se da por supuesta la división de las acciones en dos clases. De un lado, inmanentes, es decir que permanecen en el agente sin pasar a algo que sea producido, exterior y distinto del agente mismo (por ejemplo, el ver o la visión porque no pasa del vidente a otra cosa, sino que permanece en él, al igual que el entender o la intelección, que permanece en la misma potencia intelectiva); de otro, transeúntes, es decir aquellas que no se quedan en el agente, sino que pasan a otra cosa (por ejemplo, el calentar o la calefacción, que no permanece en el fuego calentante, sino que pasa al agua, cuando es calentada por el fuego). De la misma manera, siguiendo a los dos filósofos, Ripalda plantea que el entendimiento, acto vital como la visión, tiende inmanentemente o se mueve hacia dentro de sí. Así, Ripalda concibe el conocimiento como un acto personal, una acción que se produce en la persona misma. "[La] intelección consiste en una acción o un movimiento inmanente del alma

40 "Por medio de sus potencias, el alma se reviste de las formas de los objetos que conoce. Es decir, los objetos tendrían, según esta doctrina -clave para el realismo metafísico tradicional- la capacidad de influencia causal sobre nuestra mente, y esta la capacidad para asimilar intencionalmente la forma de aquellos, como la cera recibe la impresión del anillo" (Muñoz \& Velarde, 2000, pág. 427). 
con el que el entendimiento entiende o aprehende en el mismo verbo (...) la cosa o la naturaleza objetivamente existente" (D.P, q.1, lec.4, n.32).

Hasta este punto, Ripalda ha sustentado su argumentación ciñéndose de forma rigurosa a las propias tesis tomistas, como él mismo lo demuestra citando el opúsculo "Del intelecto y lo inteligible", considerado por entonces auténtico, en el que se describe el funcionamiento del intelecto humano. Pese a esto, se evidencia una clara divergencia con la auténtica doctrina tomista en lo que tiene que ver con el objeto y término del conocimiento humano, pues para Santo Tomás la acción intelectiva produce una representación fiel del objeto conocido porque es la esencia de las cosas conocidas el objeto propio del entendimiento: "el intelecto concibe las esencias tan infaliblemente como el oído percibe los sonidos y la vista los colores" (Gilson, 2002, p. 300). Así, para Santo Tomás la garantía de la objetividad del conocimiento se da en términos de la adecuación entre el intelecto y las cosas (adaequatio intellectus et rei), es decir "una adecuación o conformidad entre lo entendido por el entendimiento (cuando juzga de las cosas) y lo que las cosas son en su propia realidad" (Argote \& Del Rey Fajardo, 2007, p. 124). Esto significa que la verdad del acto intelectivo está determinada por el acuerdo entre la razón que juzga (lo cognoscente) y la realidad que afirma el juicio (lo conocido). Así, la teoría del conocimiento de Santo Tomás se define por la adecuación del intelecto a lo real, pues esto es lo que garantiza la certeza del acto intelectivo. En otras palabras, el objeto y término del conocimiento humano es para Santo Tomás la captación directa de una realidad que trasciende nuestras propias representaciones sobre las cosas.

\subsection{LA NATURALEZA DEL CONOCIMIENTO HUMANO EN JUAN MARTÍNEZ DE RIPALDA}

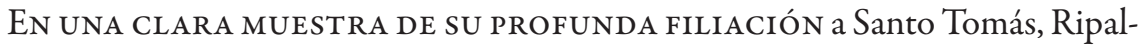
da afirma que "quienquiera que entienda, por el hecho de entender, marcha hacia algo dentro de sí mismo" (D.P, q.1, lec.4, n.34). Con esto, el jesuita afirma que el mismo entendimiento forma en sí algo para conocer la cosa entendida. En otras palabras, esto significa que concebir es presupuesto para entender, pues el entendimiento no entiende de otro modo sino concibiendo algo. Para Ripalda, la vida en acto segundo (es decir, los actos de la intelección o el entender) implica al menos alguna acción o movimiento intrínseco pues no obrar es, en su opinión, 
lo mismo que ser como un instrumento inanimado que no goza de vida alguna (D.P, q.1, lec.2, n.17). Así, aparece uno de los elementos centrales en la reflexión de Ripalda: la dimensión constructiva del entendimiento. En efecto, ante la pregunta ¿qué es aquello que concibe el entendimiento para tener noticia de las cosas? Ripalda responde que el entendimiento forma conceptos o concepciones, por las que adquiere noticia de las cosas que están fuera del alma. En otras palabras, concibe en sí algo para, con ello, adquirir noticia de las cosas fuera del alma. Basándose en la autoridad de Aristóteles y los opúsculos atribuidos a Santo Tomás, Ripalda afirma que esto surge por necesidad, pues la intelección no puede conducir a objeto alguno existente fuera del alma, y por ello debe formar algún concepto en el que se vea la cosa objetivamente existente como en un espejo: "La potencia visiva, por ejemplo, cuenta con los ojos con los que percibe las cosas que están afuera como por unas ventanas abiertas. El entendimiento carece de tales ventanas, luego entiende las cosas objetivamente en el verbo" (D.P, q.1, lec.2, n.37). Una de las características en la exposición argumentativa de Ripalda, es el uso regular de ejercicios de ejemplificación. Naturalmente, en un punto tan esencial como el de la creación de conceptos, Ripalda utiliza la analogía del intelecto con la visión o potencia visiva, para explicar cómo el concepto es el objeto en el que termina la intelección. Según Ripalda, si no se formara el concepto, en el que se ve la cosa como en un espejo, el entendimiento nunca entendería. Si el entendimiento percibiera inmediatamente la cosa existente fuera o en su naturaleza, nada más necesitaría "así como la vista ve el color en sí tal como existe en la naturaleza, sin necesitar el verbo para ver el color" (D.P, q.1, lec.5, n. 47).

Podemos concluir, entonces, que para Ripalda el conocimiento no tiene por término la intelección de las cosas mismas sino la representación de lo entendido. Así, para el jesuita el concepto objetivo de la cosa no es algo distinto del concepto o del verbo formado por el entendimiento. Esto significa que el concepto objetivo nos da a conocer el objeto en su propia naturaleza, es decir, el objeto real. De esta manera, al afirmar que el conocimiento bumano produce conceptos Ripalda hace eco un rasgo propio de la reflexión moderna sobre el conocimiento humano. El con- 
cepto es entendido por Ripalda desde una perspectiva suareciana ${ }^{41}$ que se enmarca en una corriente subjetivista del conocimiento según la cual las cosas reales en sí mismas solo pueden ser conocidas en forma mediata, es decir, en los conceptos objetivos que son representaciones o imágenes de las cosas.

Podemos sintetizar las ideas de Ripalda sobre la naturaleza del concepto en tres afirmaciones o conclusiones clave:

1. Los conceptos objetivos no se identifican con las cosas en su naturaleza real, pero nos ponen en comunicación con ella.

2. El concepto es aquello en lo que el entendimiento percibe la naturaleza de la cosa.

3. El concepto objetivo nos permite conocer las cosas en el entendimiento.

De acuerdo con estas ideas, resulta claro que para Ripalda el concepto no es solo una herramienta o un medio mediante el cual llegamos de manera inmediata al conocimiento del mundo externo tal y como es en su propia naturaleza. Por el contrario, el concepto es el medio en el cual conocemos las cosas:

Son verdaderos los siguientes asertos: Primero, el hombre no es entendido en forma primaria, inmediata y en sí según su ser real, el que tiene en su propia naturaleza. Segundo, el hombre es entendido como en un espejo, en el concepto o verbo formado, ya que el concepto es su imagen expresa. Tercero, el hombre está en dicho concepto o verbo mental objetivamente (...) Cuarto, lo que primero y de suyo conoce el entendimiento es tal concepto o verbo. (D.P, q.1, lec.1, n.9)

Así, Ripalda plantea que el concepto objetivo no es solo lo primero conocido por el entendimiento humano, sino el objeto último hacia el que tiende este. El entendimiento, entonces, forma conceptos en los que adquiere noticia de las cosas que están fuera del alma. Ripalda afirma que el entendimiento no entiende

41 Suárez distingue entre concepto formal (el acto mediante el cual el entendimiento concibe algo) y concepto objetivo (la cosa o razón representada por aquel) (Muñoz \& Velarde, 2000, p. 130). De la misma manera, Ripalda distingue entre el acto de entender o intelección, que comúnmente se llama concepto formal, y la cosa conocida o el concepto objetivo. Aunque esta distinción suareciana entre concepto formal y concepto objetivo es aceptada por los autores jesuitas neogranadinos más reconocidos, estos autores siguen pensando que el conocimiento es una relación que trasciende y termina en las cosas mismas: así, por ejemplo, el jesuita Gabriel Vásquez afirma que la verdad consiste primariamente en la conveniencia del concepto, pero no del concepto formal sino del concepto objetivo con la cosa misma tal como existe fuera (Argote \& Del Rey Fajardo, 2007, p. 122). 
inmediatamente a la cosa real existente fuera del alma sino que solamente conoce primera e inmediatamente, por ejemplo, una piedra en tanto que concebida. Ello no significa, como podría pensarse, que la acción intelectiva consiste en un proceso mental del sujeto cognoscente, encerrado en sí mismo sin necesidad de los datos del mundo sensible. Por el contrario, Ripalda afirma que es gracias a las especies sensibles de los sentidos como se forma el propio verbo o concepto de las cosas, puesto que el conocimiento no entiende de manera inmediata, sino que necesita de los datos de los sentidos para tener noticia de las cosas. Esto es, para conocer las cosas del mundo externo.

De esta manera, Ripalda apunta hacia un problema propio de la teoría del conocimiento en clave moderna como es la contraposición sujeto cognoscente/ objeto del conocimiento, en la que ese sujeto realiza una actividad interna en relación con el carácter externo con el que se califica el objeto del conocimiento. En esta contraposición entre uno y otro elemento, surge la pregunta ontológica en torno a la existencia de las cosas en sí mismas, en su naturaleza bien de manera dependiente o bien de manera independiente respecto del sujeto cognoscente. Frente a este problema, las respuestas posibles que se dieron en la teoría del conocimiento moderna, alternaron entre una y otra. $\mathrm{Al}$ respecto, Muñoz \& Velarde (2000) sostienen:

La alternativa realista en ontología sería la que asume que el mundo externo existe con independencia del sujeto cognoscente (...) de modo tal que ponga la realidad del sujeto cognoscente en un mundo aparte respecto del mundo conocido p.e., como dos órdenes substanciales diferentes, como ocurre en las diversas versiones del racionalismo continental moderno. Por otro lado, las alternativas gnoseológicas coherentes con el principio de la independencia existencial del mundo externo serían aquella según la cual el conocimiento no implicaría en principio transformación del mundo conocido por parte del sujeto cognoscente, de suerte que este se limitase a reflejar o representar de algún modo dicho mundo (lo que por lo común suele caracterizarse como realismo ingenuo o acrítico). (p. 408)

Esta tesis de Ripalda, en la que se plantea que las cosas reales que existen fuera del alma no son alcanzadas inmediatamente por el entendimiento, parece ir en contravía de la doctrina del realismo ingenuo y acrítico que habla simplemente de una asimilación o representación pasiva del mundo externo, pues plan- 
tea que ese mundo externo, el mundo de lo conocido, aunque existe de manera independiente a los sujetos cognoscentes, solo será accesible al conocimiento dependiendo de la actividad cognoscitiva que lleva a cabo el entendimiento humano. Según su ejemplo del espejo ${ }^{42}$, Ripalda plantea que lo que sucede en el espejo es, de manera análoga, lo que sucede en el acto cognitivo, en el cual lo que primero conoce el entendimiento no es la cosa que existe fuera del alma, sino solamente el concepto o la concepción que forma el entendimiento de la cosa existente. Es esta formación de conceptos, como veíamos, no solo la actividad propia del entendimiento sino aquello hacia lo que tiende, en su acción intelectiva, el lugar donde termina el acto de comprensión. En otras palabras, el objeto de conocimiento no es otra cosa que la formación de conceptos objetivos, según Ripalda, "el concepto objetivo, según el modo común de hablar, es aquello donde termina el entender o la intelección; es así que, según enseña $S$. Tomás, la intelección termina en el verbo. Luego el concepto objetivo consiste en el verbo del entendimiento (...) Formando, pues, el verbo de hombre, conoce al hombre, y formado el verbo de la piedra, entiende la piedra" (D.P, q.2, lec.2, n.60). Ripalda nunca pone en duda que esta sea la opinión propia de Aristóteles y Santo Tomás, dada la completa autenticidad otorgada por entonces a los opúsculos en los que basa su argumentación. Así, por ejemplo, prueba sus conclusiones sobre el conocimiento humano citando los opúsculos donde se afirma que "lo así, pues, formado y expresado en las almas, se llama verbo interior, no como aquello con lo que (quo) el entendimiento entiende, sino en lo que (in quo) entiende. Porque en lo así formado y expresado ve la naturaleza de la cosa entendida" (D.P, q.2, lec.2, n.61). A partir de estas fuentes, atribuidas a Santo Tomás, Ripalda infiere las siguientes tres conclusiones:

1. El concepto objetivo es aquello que es conocido.

2. La naturaleza que se conoce es conocida en el verbo y no en la naturaleza existente fuera del entendimiento.

3. El concepto objetivo no puede ser la cosa existente fuera del alma.

42 "Así como mirando al espejo que está enfrentado a Pedro, a quien tengo detrás, lo que primero y de suyo contemplan mis ojos no es al mismo Pedro que tengo detrás, sino tan sólo la imagen que tengo de Pedro que está en el espejo" (D.P, q.1, lec.1, n.9). 
Con estas afirmaciones, Ripalda se sitúa en una perspectiva no ingenua ni acrítica, sino en una alternativa epistemológica cercana a la modernidad filosófica ${ }^{43}$ que "conjuga el principio ontológico general de la independencia existencial con el principio gnoseológico de la (inter)dependencia cognoscitiva” (Muñoz \& Velarde, 2000, p. 408), puesto que el conocimiento humano no solo descubre o representa el mundo externo sino que, ante todo, lo vuelve objetivo gracias a la formación de conceptos que permiten entenderlo.

\section{Conclusiones}

Hemos situado la obra de Juan Martínez de Ripalda tanto en su contexto específico como en su intencionalidad jurídica, para demostrar cómo la controversia doctrinal con los dominicos no responde a un contexto ingenuo de disputas académicas. En ese sentido, hicimos eco del análisis de José Luis Fuertes Herreros sobre la escolástica jesuita barroca, quien plantea que entre 1599 y 1659 la Compañía de Jesús surge como una escuela con una identidad y una doctrina propia que, debido a su propuesta de renovación escolástica, va generando cierta tendencia anti jesuítica generalizada que se manifiesta de manera clara no solo en la polémicas teológicas europeas sobre el probabilismo y los planteamientos políticos suarecianos (Saranyana, 2005, pp. 33-34), sino en los pleitos por las prebendas y favores universitarios reales, como el que tuvo lugar durante todo el siglo XVII entre la Universidad Javeriana y la Universidad de Santo Tomás en la Nueva Granada. En este contexto de disputas jurídicas entre las dos comunidades, surgió una acusación de carácter doctrinal por parte de los dominicos contra la Compañía de Jesús, que no solo agudizaba el ya largo conflicto en la Nueva Granada, sino que evidenció la ya mencionada malquerencia generalizada hacia el tomismo renovado defendido por los jesuitas, como lo demuestra el juramento de la Universidad de Salamanca que, a la vez que suponía una reafirmación en la au-

43 "Desde la Edad Media se abrió camino una tendencia a hacer del contenido inteligible del concepto un objeto propio del conocimiento, distinto de la cosa conocida por el concepto. Esta decisión de algunos maestros, más bien oscuros, no tuvo importancia hasta el día en que, atendiendo a las exigencias de su método matemático, Descartes se apropió de la noción de concepto objetivo o realidad objetiva del concepto, entendiendo por ello la realidad misma en tanto que representada en y por el concepto" (Gilson, 1974, p. 152). 
toridad filosófica de Santo Tomás y San Agustín, se asumía como un rechazo del nuevo modo de hacer teológico y filosófico que propugnaba la Compañía de Jesús en sus centros de enseñanza. Como vimos, la respuesta jesuita a la controversia universitaria se da, en la obra de Juan Martínez de Ripalda, en términos doctrinales, para demostrar la idoneidad y suficiencia académica de la Compañía de Jesús para enseñar las tesis oficiales del tomismo y, por ende, convertirse en Universidad de Estudios Generales con toda la potestad para otorgar grados académicos en el territorio de la Nueva Granada. Por ello, la estructura de la obra de Ripalda es la de un curso filosófico completo en el que se intenta dar cuenta de la profunda filiación tomista que subyace a la enseñanza jesuita de todos los grandes temas académicos propios de la filosofía escolástica: Lógica, Física y Metafísica. Sin embargo, aunque la intencionalidad es clara, lo que aparece en la obra de Ripalda, por lo menos en su Disertación Previa, no es una lectura completamente fiel y exacta de las principales doctrinas tomistas, sino una enunciación en clave moderna de la naturaleza del conocimiento humano. El hecho de que este tipo de enunciaciones modernas estén presentes en la filosofía escolástica neogranadina del siglo XVII, nos permite suponer que el juicio historiográfico tradicional sobre la filosofía en Colombia puede actualizarse con la recuperación, traducción e investigación de los manuscritos filosóficos elaborados por miembros de las órdenes religiosas establecidas en la Nueva Granada. Con el análisis de estas fuentes es posible demostrar que no se puede desconocer el momento colonial como un presente enunciativo en la condición histórica y epistemológica de la modernidad occidental. En otras palabras, es claro que la narrativa europea de la modernidad tiene una cara oculta y más oscura, en palabras de Mignolo (1995), "la colonialidad que es constitutiva de la modernidad: sin colonialidad no hay modernidad" (p. IX). Asimismo, la aparición de enunciaciones modernas en textos coloniales neogranadinos hace pensar que al discurso predominante de una modernidad, en singular, puede contraponerse con el de modernidades heterogéneas que permitan ampliar las posibilidades críticas sobre las representaciones dominantes de lo moderno. Desde esa renovada perspectiva, es posible que las cuestiones relativas a la Colonia en América Latina puedan dejar de ser vistas como el eje central de un pasado borroso y distante o como temas anacrónicos de estudios propios de eruditos especializados en un período lejano y ya olvidado de la historia latinoamericana (Mignolo, Banerjee Dube, \& Dube, 2004, p. 56). En 
consonancia con estas orientaciones, la Biblioteca Virtual del Pensamiento Filosófico en Colombia de la Universidad Javeriana, surge como un proyecto investigativo innovador y oportuno para la resignificación del patrimonio filosófico colonial en nuestro país a través de la recuperación de manuscritos y textos filosóficos neogranadinos de las órdenes religiosas. Gracias a su trabajo en la digitalización y traducción de la obra de Juan Martínez de Ripalda, fue posible ubicar al jesuita en su justa dimensión histórica y apostar por una exégesis filosófica que permitiese esbozar la originalidad de sus planteamientos sobre el conocimiento humano a la luz de la apuesta humanista de la Compañía de Jesús. Sea este un pequeño aporte para la investigación del aun inexplorado legado filosófico heredado de los autores neogranadinos.

Referencias

Alonso, M. d. (1945). Colección completa de las encíclicas de su Santidad León XIII. Valladolid: Cuesta.

Annick, L. (2004). El paradigma colonial en la historiografía latinoamericanista. Istor. Revista de Historia Internacional, 107-128.

Aquino, S. T. (2001). Opúsculos y cuestiones selectas. (A. Osuna Fernández, Ed.). Madrid: Biblioteca de Autores Cristianos.

Argote, G. M., \& Del Rey Fajardo, J. (2007). Vida, obra y pensamiento de Juan Martinez de Ripalda (1641-1707). Bogotá: Pontificia Universidad Javeriana. Argote, G. M. (2000). La filosofía escolástica de los siglos XVII-XVIII en el Nuevo Reino de Granada. Bogotá: El Búho.

Ariza, A. (1993). Los dominicos en Colombia. Bogotá: Ánthropos.

Ariza, F. A. (1980). El Colegio-Universidad de Santo Tomás de Aquino de Santa Fé de Bogotá. Bogotá: Kelly.

Astrain, A. (1920). Historia de la Compañía de Jesús en la asistencia de España. Madrid: Administración de razón y fe.

Copleston, F. (1981). Historia de la filosofía. Barcelona: Ariel.

Copleston, F. (1976). Elpensamiento de Santo Tomás. México: Fondo de Cultura Económica. 
Cruz Vélez, D. (1977). Aproximaciones a la filosofía. Bogotá: Instituto Colombiano de Cultura.

Fajardo, J. (2011). La Facultad de Jurisprudencia de la Universidad Javeriana 1706-1767. Bogotá: Pontificia Universidad Javeriana.

Fajardo, J. (2010). Los precursores de la Sociedad del Conocimiento en la Javeriana Colonial. Bogotá: El Búho.

Fernández, C. (1986). La filosofía escolástica de los siglos XVIy XVII. Madrid: BAC.

Fuertes Herreros, J. L. (2006). La escolástica del Barroco: presencia del Cursus Conimbricensis en el Pharus Scientarum (1659) de Sebastián Izquierdo. Rencontres de Philosophie Médiévale, pp. 159-200.

Gilson, E. (2002). El tomismo: introducción a la fllosofía de Santo Tomás de Aquino. Pamplona: Universidad de Navarra.

Gilson, E. (1974). Lingüistica y filosofía. Madrid: Gredos.

Herrera, D. (1979). La filosofía en la Colonia. Elementos para una aproximación histórica. Ideas y Valores, 28(55-56), pp. 58-81.

Hernández de Alba y Lesmes, G. (1969). Documentos para la historia de la educación en Colombia. Bogotá: Patronato Colombiano de Artes y Ciencias.

Marquínez Argote, G., \& Beuchot, M. (1996). La filosofía en la América colonial. Bogotá: El Búho.

Medina, M. A. (1992). Los dominicos en América. Madrid: Mapfre.

Mignolo, W. (1995). The Darker Side of the Renaissance: Literacy, Territoriality and Colonization. Ann Arbor: University of Michigan.

Mignolo, W., Banerjee Dube, I., \& Dube, S. (2004). Modernidades coloniales: otros pasados, historias presentes. México: El Colegio de México.

Muñoz, J., \& Velarde, J. (2000). Compendio de epistemología. Madrid: Trotta.

Pacheco, J. M. (1959). Los Jesuitas en Colombia. Bogotá: Universidad Javeriana.

Pinzón Garzón, R. (1987). La filosofía en Colombia. Bibliografía de los siglos XVI, XVII y XVIII. Bogotá: Universidad Santo Tomás.

Plata Quesada, W. E., \& Reyes Escobar, N. C. (2005). La Universidad de Santo Tomás de Colombia ante su historia: Siglos XVI-XIX. Bogotá: Editorial Universidad Santo Tomás. 
Quecedo, F. (1952). Manuscritos teológico-filosóficos coloniales santafereños. Ecclesiastica Xaveriana, 2, pp. 191-294.

Ramírez, F. (2002). Notas para una historia de la Universidad Javeriana colonial. A. H. Pacheco, Memoria del Primer Encuentro de Archiveros e Investigadores de la Historia de la Compañia de Jesús en Colombia (pp. 161-170). Bogotá: Universidad Javeriana.

Ramírez, F. (1988). La filosofía en la Colonia. IV Congreso Internacional de Filosofia Latinoamericana. Tendencias actuales de la filosofía en Colombia (p. 59). Bogotá: Universidad Santo Tomás.

Rodríguez Cruz, A. M. (1973). Historia de las universidades hispanoamericanas (Periodo hispánico). Bogotá: Instituto Caro y Cuervo.

Salazar, J. A. (1946). Los estudios eclesiásticos superiores en el Nuevo Reino de Granada (1563-1810). Madrid: Consejo Superior de Investigaciones Científicas.

San-Pedro Rodríguez, L. E. (2006). Historia de la Universidad de Salamanca. Salamanca: Universidad de Salamanca.

Saranyana, J.-I. (2005). Teología en América Latina (Vol. II). Madrid: Iberoamericana.

Silva, R. (2004). Saber, cultura y sociedad en el Nuevo Reino de Granada. Siglos XVII y XVIII. Medellín: La Carreta.

Silva, R. (1992). Universidad y sociedad en el Nuevo Reino de Granada. Bogotá: Banco de la República.

Torchia Estrada, J.C. (1979). La escolástica colonial en América Latina. Revista de Filosofia Latinoamericana, 5(2) pp. 141-178. 